\title{
OBSERVAÇÕES SOBRE ATIVIDADE DE MOSQUITOS CULICIDAE, EM MATA RESIDUAL NO VALE DO RIBEIRA, S. PAULO, BRASIL *
}

\author{
Oswaldo Paulo Forattini** \\ Almério de Castro Gomes ** \\ Jair Lício Ferreira Santos** \\ Eunice Aparecida Bianchi Galati** \\ Ernesto Xavier Rabello** \\ Délsio Natal **
}

\begin{abstract}
FORATtinI, O. P. et al. Observacões sobre atividade de mosquitos Culicidae, em mata residual no vale do Ribeira, S. Paulo, Brasil. Rev. Saúde públ., S. Paulo, $15: 557-86, \quad 1981$,
\end{abstract}

RESUMO: Relatam-se observaçōes sobre o ciclo diário de atividade, por parte de mosquitos Culicidae de mata residual, em área de ambiente intensamente modificado por exploração agropecuária, no Vale do Ribeira, Estado de São Paulo, Brasil. Foram levadas a efeito, com ritmo bimensal, capturas ininterruptas de vinte e cinco horas com isca humana, além de coletas simultâneas com ardilhas tipo Shannon em ambiente intra e extra florestal. Os resultados evidenciaram o caráter diurno e noturno das espécies mais freqüentes, com destaque para o Ae. scapularis e Ae. serratus que, embora com atividade classificada como diurna, mantêm atuação apreciável também durante a noite. Em relação ao primeiro acrescenta-se a ocorrência de nítido pico endocrepuscular vespertino, e a manutenção de sua presença no meio extraflorestal. De maneira geral, essas duas espécies mostram-se presentes todos os meses do ano, com dominância de Ae. scapularis sobre Ae. serratus somente no mês de junho, ocasião porém em que aquele sobrepuja a este de maneira considerável. Tais feições caracterizam quadro que permite atribuir àquele mosquito maiores oportunidades de contato com a população humana e, por conseguinte, papel importante na veiculação de arboviroses, em especial modo, de encefalites.

UNITERMos: Culicidae, ecologia. Aedes scapularis. Aedes serratus. Arboviroses. Vale do Ribeira, SP, Brasil.

\section{INTRODUÇĀO}

$O$ caráter ritmico das atividades de culicídeos constitui fenômeno que tem sido objeto de investigações freqüentes. Dentre as estudadas sob esse ponto de vista, destaca-se a concernente à alimentação sanguii- nea, cujas variações diárias parece obedecerem a comando endógeno (Clements *, 1963). Contudo, desde que impossivel excluir a influência exógena, admite-se que o comportamento resultante representaria a combi-

- Trabalho realizado com suporte financeiro do Convênio entre a Universidade de São Paulo/ /Faculdade de Saúde Pública e o Ministério da Saúde (Centro Brasileiro de Estudos Entomo. lógicos em Epidemiologia - CENTEP).

* Do Departamento de Epidemiologia da Faculdade de Saúde Pública da USP - Av. Dr. Arnaldo, 715 - 01255 - São Paulo, SP - Brasil. 
FORATTINI, O.P. et al. Observaçóes sobre atividade de mosquitos Culicidae, em mata residual no Vale do Ribeira, S. Paulo, Brasil, Rev. Saúde públ., S. Paulo, 15:557-86, 1981.

nação de efeitos dessas duas origens. Conseqüentemente, o quadro de atividades sofre sempre ajustamento por parte das características imediatas do ambiente (Saunders 27,28, 1976, 1981). De qualquer maneira, é óbvia a importância de que se revestem os conhecimentos sobre o exercício da hematofagia por parte desses mosquitos, uma vez que possibilitam melhor entendimento da transmissão de infecções por eles veiculadas.

Em publicações anteriores relatou-se as observações levadas a efeito na área do Vale do Ribeira, Estado de São Paulo, Brasil, visando a fauna culicidea regional. Foram iniciadas em decorrência de surto de encefalite que atingiu a regiāo (Forattini e col. ${ }^{7,8}, 1978$ ). Nessa oportunidade, pôde-se verificar, em ambientes extra e intradomiciliares, as composiçōes específicas e as freqüências como subsídios para o objetivo de identificação de possiveis populações vetoras daquela virose. Em sequiência, impunha-se 0 estudo das características hemófilas, no sentido de detectar-lhe seus aspectos rítmicos diários ou nictemerais.

Assim sendo, interessou de início observar o comportamento em relação à isca humana. Com finalidade comparativa, levou-se a efeito simultâneas observaçōes com o emprego de outras técnicas de coleta. Em relação ao ambiente, escolheu-se o extradomiciliar representado por local de vegetação residual, em área de intensa atividade agrária.

\section{CARACTERISTICAS LOCAIS}

A localidade onde foram levadas a efeito estas observações é representada pela Fazenda Experimental de Pariquera-Açú (Estação Experimental do Vale do Ribeira), e pertencente ao Instituto Agronômico de Campinas, da Secretaria da Agricultura do Estado de São Paulo. Como já se mencionou, quando da descrição geral da região, a ela é próprio o aspecto de ambiente alterado, com a presença de matas residuais em níveis baixos (Forattini e col. ${ }^{7}$, 1978). A sua localização geográfica corresponde a $27^{\circ} 30^{\prime}$ de latitude sul e $47^{\circ} 50^{\prime}$ de longitude oeste.

Por um dos lados, essa área limita com - rio Jacupiranga e, em sentido diagonal, é atravessada, na altura do $\mathrm{km} \mathrm{200,} \mathrm{pela}$ pista da rodovia que liga as cidades de São Paulo e Curitiba. O lado oposto àquele é representado pela antiga estrada que conduz à sede do município de Pariquera-Açú. Os demais são limitrofes a outras propriedades onde se observa feição paisagística análoga. Esta, como se mencionou, é formada por terrenos cultivados e entremeados de matas residuais. Tais restos de cobertura florestal conservam aspectos primários, em grau variável. Para alguns, estes são mais acentuados, como o revela a maior presença, que neles se observa, de árvores com elevado porte. Para outros, submetidos que foram a alterações mais acentuadas, a cobertura vegetal é predominantemente constituída por individuos arbóreos mais baixos e de troncos de menor diâmetro. Assim sendo, para a execusão destes trabalhos, selecionou-se área de mata residual dentre as possuidoras de características mais primitivas. A escolha recaiu sobre pequena "mancha" situada à margem da mencionada rodovia, de contorno retangular com os lados medindo 150 e 200 metros, aproximadamente. Os dados apresentados nesta descrição podem ser apreciados na Fig. 1.

Os motivos que levaram a sediar as investigações nessa localidade, objetivaram a observação do comportamento de mosquitos em área modificada e situada na planície do Vale do rio Ribeira de Iguape. Nesse particular, a citada Estação Experimental oferece condições particularmente propícias. Eis que, além de sua utilização para plantio e experimentaçāo de técnicas agrícolas várias, nela projetou-se a instalação de pôlder. Esta teve seu começo no decurso do primeiro semestre de 1977, ocasião em que se procedeu à drenagem do solo e à formação de canais. Seguiu-se a construção das quadras para as culturas. Embora a obra não estivesse inteiramente concluída, 
FORATTINI, O.P. et al. Observações sobre atividade de mosquitos Culicidae, em mata residual no Vale do Ribeira, S. Paulo, Brasil, Rev. Saúde públ., S. Paulo, 15:557-86, 1981.

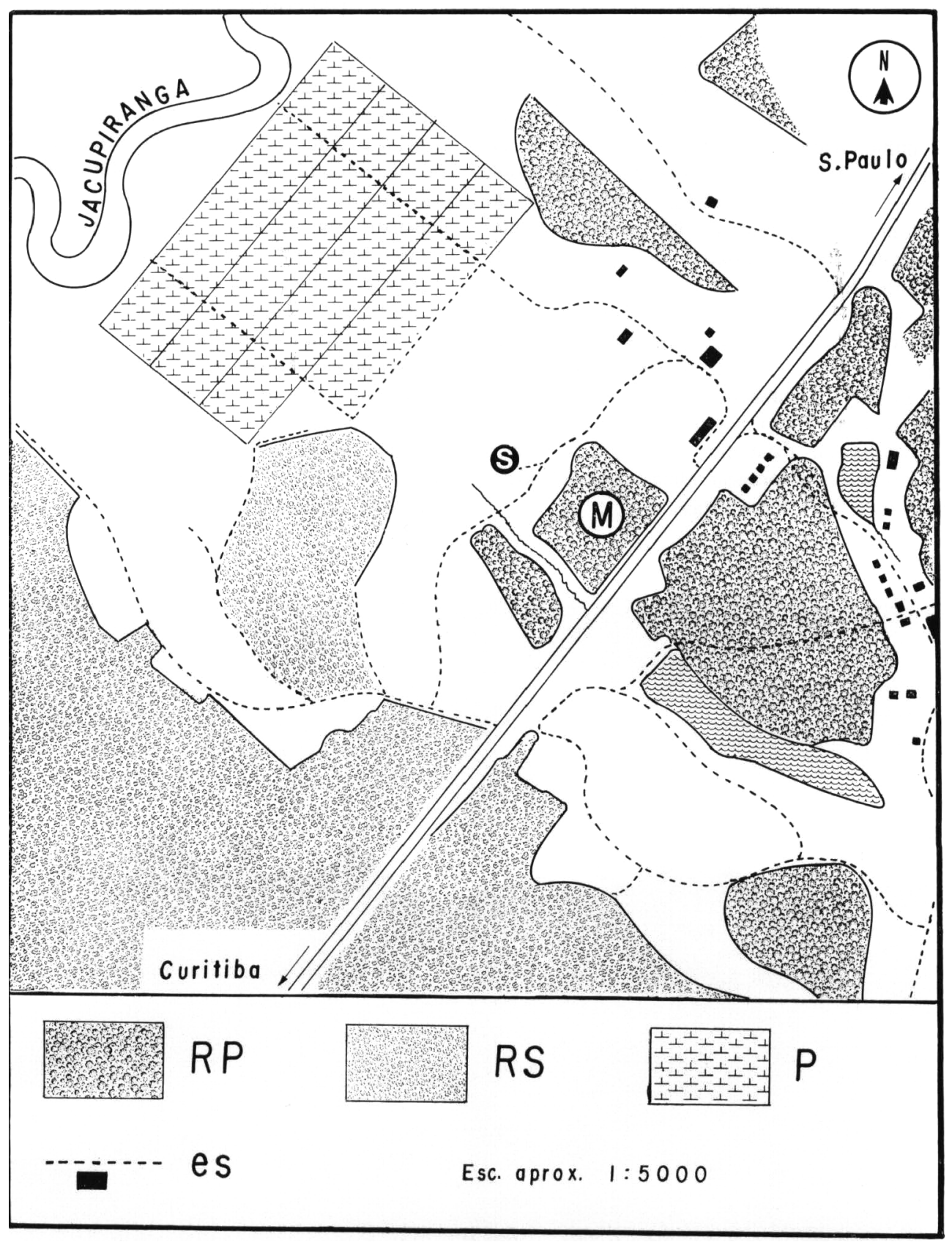

Fig. 1 - Representação esquemática da área estudada na Fazenda Experimental de Pariquera-Açú (Estação Experimental do Vale do Ribeira). M - mancha de mata residual onde foram realizadas as observaçōes. $P$ - pôlder. RP - mata residual com predominio de elementos arbóreos primários. RS - mata residual com predomínio de elementos arbóreos secundários. S - localização da armadilha tipo Shannon, em local aberto. es - edificações e estradas secundárias. 
FORATTINI, O.P. et al. Observaçôes sobre atividade de mosquitos Culicidae, em mata residual no Vale do Ribeira, S. Paulo, Brasil, Rev. Saúde públ., S. Paulo, 15:557-86, 1981.

o sistema de irrigação foi testado em dezembro daquele ano. A partir do inicio de 1978 quando pois, como se verá adiante, estas pesquisas estavam começando, passou-se ao cultivo de cereais, principalmente arroz e milho. Até o momento, correspondente ao primeiro trimestre de 1980 , as obras ainda não estavam completas, permanecendo inconclusa a barragem. De qualquer modo, trata-se de localidade em processo de acentuada modificação ambiente para fins agricolas. Isso vai ao encontro dos propósitos das presentes pesquisas uma vez que, como se referiu, pretende-se verificar a possivel influência dessas alterações na composição e no comportamento da fauna culicídea ali existente. As Figuras 1 a 5 destinam-se a fornecer idéia sobre as características locais descritas.

\section{MATERIAL E METODOS}

As coletas com isca humana foram levadas a efeito ao nivel do solo no interior do ambiente da floresta residual supradescrita e principiaram em janeiro de 1978, tendo-se prolongado até março de 1980. Durante esse espaço de tempo, obedeceu-se a ritmo bimensal que incluia duas semanas alternadas. Em cada umá procedeu-se à realização de captura com a duração de 25 horas ininterruptas, e que se iniciava às 10:00 da terça-feira encerrando-se às 11:00 do dia seguinte. A utilização desse número de horás, ao invés de vinte e quatro, deveu-se à possibilidade de ocorrência do assim denominado "efeito de intrusão" (Haddow ${ }^{14}$ 1954; Germain e col 10 1972). Seria o responsável por eventual maior afluência de

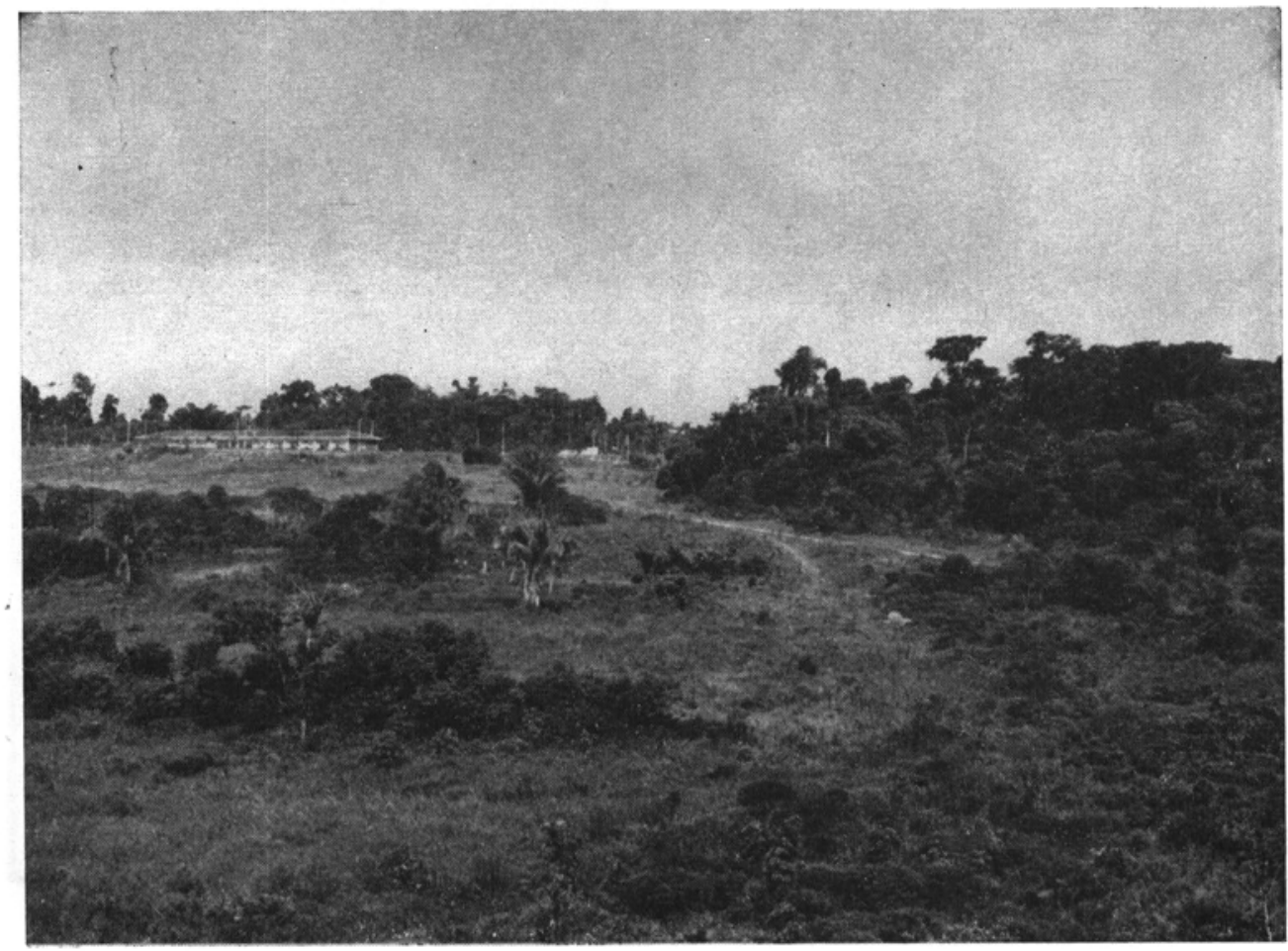

Fig. 2 - Aspecto da área estudada na Fazenda Experimental, podendo-se ver à direita, parte de mata residual que foi escolhida para a realização das coletas. 
FORATTINI, O.P. et al. Observaçóes sobre atividade de mosquitos Culicidae, em mata residual no Vale do Ribeira, S. Paulo, Brasil, Rev. Saúde públ., S. Paulo, 15:557-86, 1981.

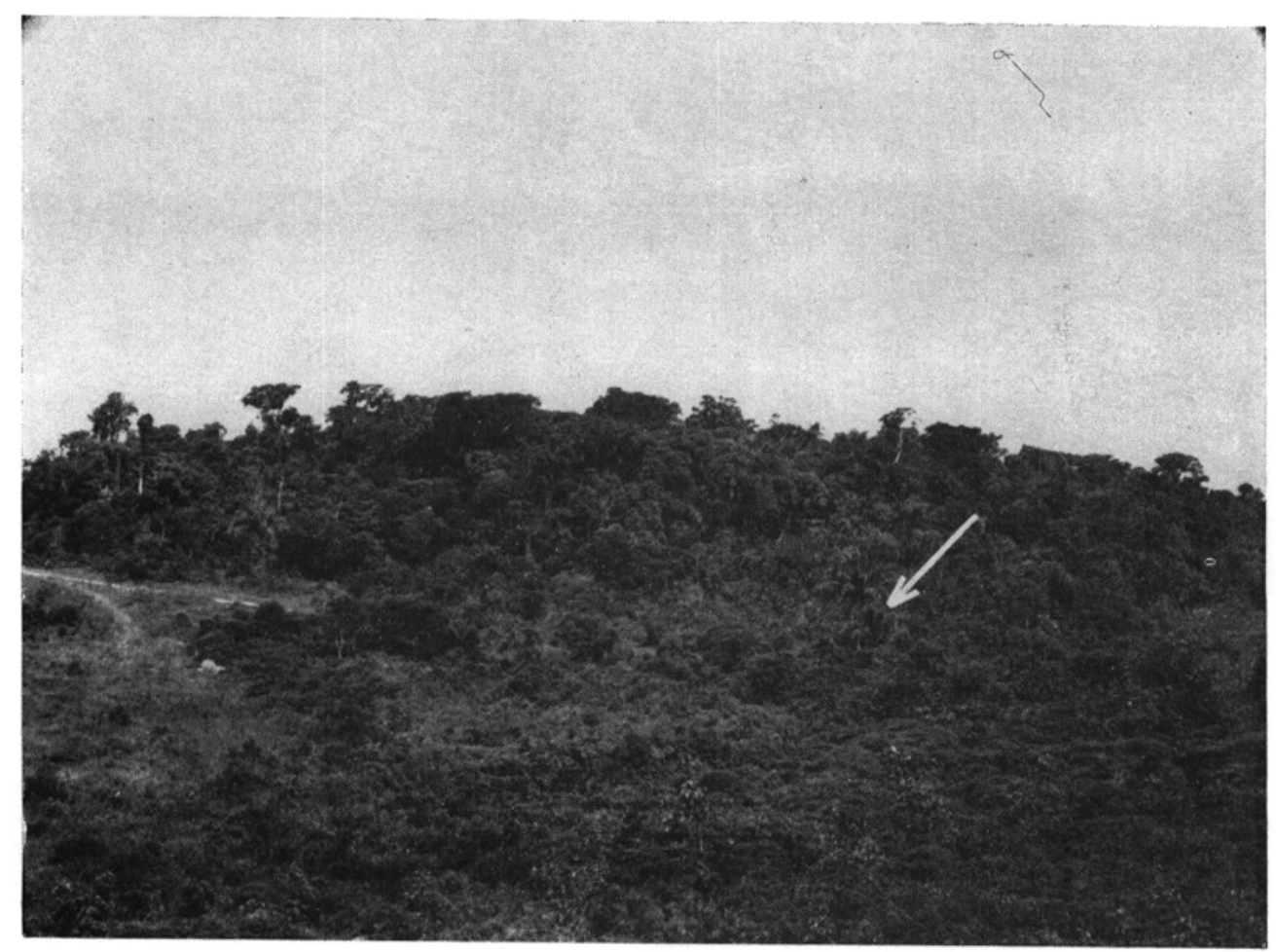

Fig. 3 - Mata residual onde foram levadas a efeito as observaçōes. Em primeiro plano, à direita, e assinalado pela seta, observa-se o local de operação da armadilha tipo Shannon, em área aberta.

mosquitos no decurso da primeira hora. E isso, possivelmente estimulado pela agitação inerente ao inicio das atividades e da presença humana locais, ensejando seleção passiva ou oportunística por parte desses hematófagos (Colless ${ }^{5}$ 1957; Aitken e col. ${ }^{1}$ 1968; Kruijf 19 1972; McCrae e col.22 1976).

As iscas humanas foram representadas pelos próprios componentes da equipe de captura, coletando os espécimens que pousavam em seus membros inferiores. Foram utilizados tubos de clorofórmio e, mediante sistema de revezamento, assegurou-se a atividade constante de dois capturadores. Para obviar possíveis dificuldades decorrentes de chuvas prolongadas, as capturas foram realizadas embaixo de telheiro adrede construido para essa finalidade. Os mosquitos assim obtidos foram reunidos em lotes referentes a cada hora, como periodo máximo.

A atividade foi avaliada mediante o cálculo das médias de Williams $\left(\overline{\mathrm{X}}_{\mathrm{w}}\right)$ de acordo com a definição de Haddow ${ }^{14,15}$ (1954, 1960). Essa medida de tendência central é recomendado neste tipo de investigações onde a regularidade de ocorrência das espécies é tão importante quanto o próprio número respectivo de indivíduos coletados. 

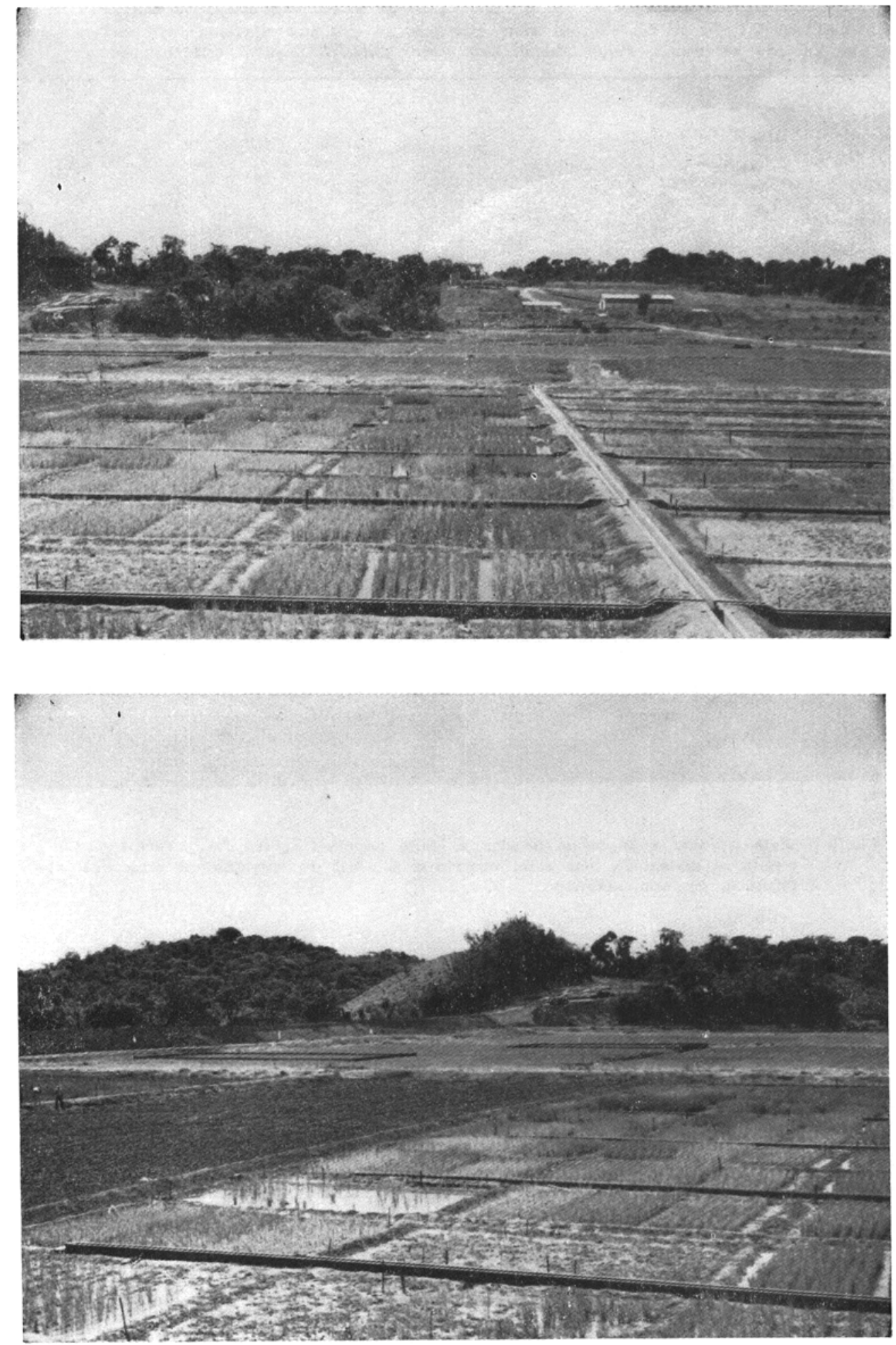

Figs. 4 e 5 - Aspectos panorâmicos do pôlder, com os canteiros de cultivo. 
FORATtiNi, O.P. et al. Observaçós sobre atividade cle mosquitos Culicidae. em mata residual no Vale do Ribeira. S. Pailo. Brasil, Rex. Saide públ., S. Paulo. 15:557-86, 1981.

Assim, pois, os cálculos foram teitos con a cmprego da seguinte formula:

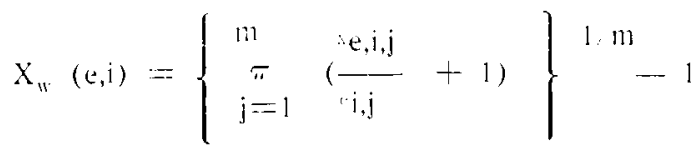

onde:

$\bar{X}_{w}(e, j)=$ média referente à espécite no intervalo $i$.

Xe, $\mathrm{i}, \mathrm{j}=$ numero de espécimens da espécic $e$. coletados na captura $j$ realizada no intervalo de tempos $i$.

ni = numero de capturas realizadas no intervalo de tempo $i$.

$\mathrm{C}, \mathrm{j}=$ numero de individuos capturadores empregados na captura j realizada no intervalo de tempo $i$

$\mathrm{Na}$ presente pesyuisa os tempos (i) foram representados por intervalos constituidos pur horas, creps (definidos adiante) e mese: Púra a comparação das médias entre esses vários períodos de tempo referentes a uma mesma espécie, ou para comparar ats correspondentes a várias espécies dentro de um mesmo intervalo de tempo, procedell-se ao cálculo da percentagem de cada média em relação à soma das médias obtidas. Dessa maneira, esse cálculo percentual (P) obedeceu à seguinte fórmula:

$$
P_{(e, i)} \frac{x_{w}(e, i)}{\sum_{i=1}^{n}} \times 100
$$

onde $n$ corresponde ao numero total de intervalos de tempo en cada captura considerada.

A partir de maio de 1978, procurou-se particularizar o comportamento crepuscular dos culicídeos, tanto vespertino como matutino. Visou-se; com isso, detectar possivel ocorrência de picos de atividade nesses períodos de mudança gradual de luminosidade, a exemplo do que se verifica en oitias regiōes, onde se detectou secüuencia de ondas crepusculares especificas (Lumsdem :1 1952; Haddow 14 1954; Haddow e col. ${ }^{1+}$ 1968). Para tanto, procedeu-se ao cálculo desses períodos, lançando-se mão dos dados publicados no Almanaque Náutico. "A sua duração foi previamente determinada, mediante interpolaçāo, para a latitude do lugar de trabalho e os dias de captura previstos. A esses resultados foram adicionados 11 min. relativos à diferença entre a hora oficial do Brasil e a real, esta correspondente à longitude local. Foran assim conhecidos os horários de inicio e fmin desses intervalos crepusculares. Todavia, haveria de se levar em contá as variaçies que esses espaços de tempo sofrem de acordu con a época do ano, o que requeria necessariamente padronização nessas medidas de tempo. Isso rcalizado mediante a utilização da unidade crep correspondente à variação da intensidade luminosa crepuscular de acordo con os conceitos de Nielsen "4.2. (1961, 1963). Assim sendo, a transformação, da medida usual em hora; e minutos, em creps, foi feita por intermédio de relaçōes que levaram em conta a hora do dia, o início, o fim $e$ a duração do intervalo crepuscular, da maneira seguinte:

a) crepúsculo vespertino:

$$
\text { crep }=\frac{\text { hora do dia }- \text { inicio }}{\text { duração }}
$$

b) crepúsculo matutino:

$$
\text { crep }=\frac{\text { fin }- \text { hora do dia }}{\text { duração }}
$$

Assim sendo, para o crepúsculo respertino, 0 inicio do intervalo correspondeu ao crep 0,0 e o fim ao crep 1,0 , enquanto para 0

* Edita 'o pelo Minsterio da Marinha. 
FORATTINI, O.P. et al. Observaçóes sobre atividade de mosquitos Culicidae, em mata resid al no Vale do Ribeira. S. Pailo, Brasil, Rei. Sailde públ., S. Paulo, 15:557-86, 1981.

matutino esses valores foran, respectivamente referentes aos creps 1,0 e 0,0 . Em ambos, às horas noturnas correspondem valores positivos e às diurnas negativos.

Estabelecida essa orientação, a maior dificuldade nos estudos do comportamento crepuscular dos mosquitos residiu nos trabalhos de campo. Com efeito, em tais circunitâncias, à leitura dos tempos em condiçôes precárias de luminosidade, soman-se dificuldades adicionais devidas ao fato de que os inicios e os internavlos de captura devem ser constantes em relaçāo à unidade crep ¿ nâo ao horário local. Os erros dai decorrentes poderiam ser de apreciável monta, comprometendo excessivamente os resultados. Face a tais fatos, adotou-se procedimentu mais cômodo e preciso. Assim sendo, os capturadores, informados previamente sobre os horários de inicio e fim dos periodos crepusculares, trabalharam sempre com a hora local e com espaços de tempo em minutos, ignorando unidades e intervalos creps. A partir de algum momento conveniente, anterior ao inicio do crepúsculo, procedeu-se a capturas com intervalos de 5,0 min. num total de, pelo menos, seis coletas. Isso garantiu a cobertura integral dos crepúsculos uma vez que estes nunca foran superiores a $30,0 \mathrm{~min}$. de duração. A esse espaço de tempo designou-se como "periodo crepuscular". Anotou-se, também, as coletas levadas a efeito nos denominados "minutos anteriores" e "minutos posteriores" e que corresponderam, respectivamente, aos intervalos que mediaram entre as horas inteiras mais proximas e o inicio e o fim dos "periodos crepusculares". Além disso, foran tambem anotadas as capturas na hora imediatamente anterior e posterior a esses respectivos "minutos anteriores" e "minutos po. teriores". Desse modo, registraram-se as coletas realizadas em dez intervalos de tempo consecutivos, durante cada captura crepuscular. Para cada um deles calculou-se o crep médio, ou seja, o correspondente à média entre os valores crep proprios do inicio e do fim. A seguir, procedeu-se à distribuição de freqüências desses creps médios e das respectivas capturas em intervalos creps de $-5,0$ a 6,0 , dispostos simetricamente em torno do crepúsculo o qual, como se viu, corresponde aos valores de 0,0 a 1,0 dessas unidades. Tal disposição foi feita de maneira a situar amplitudes menores no "periodo crepuscular" e maiores a medida que se afastam, objetivando assim melhor detectar o comportamento durante esse conjunto de tempo. Dessa maneira, a Tabela 1 apresenta a distribuição percentual de 84 capturas ( 44 vespertinas e 40 matutinas), realizadas com vistas à atividado crepuscular, por intervalos creps.

Claro está yue esse procediniento não fez corresponder exatamente o numero capturado durante certo intervalo crep ao numero que seria obtido se, no campo, fosse utilizada essa unidade de tempo. Todavia, acredita-se que os erentuals desvios foram pequenos e menores do que us yu resultariam das dificuldades uperacionas já mencionadas.

Os intervalos de tempo en unidades horárias, anteriormente definicos, diteriram entre si não apenas no mesnu dia conu nos diferentes dias de coleta. Assim è yuc os "minutos, anteriores e posteriores", variaran de mínimo $5,0 \mathrm{~min}$. a maximo de 60,0 min. Assin, antes do cálculo das medas para cada intervalo crep, tornou-se necessário obter o numero padronizadr cie mosquitos capturados por alguma inidade do tempo. Optou-se pela unidade de 5,0 min., correspondente ao menor espaço de tenıp, utilizado. Assim, tendo-se coletado $X c, l, j$ indiriduos da espécie $e$, no periodo de tempo $i$, e na captura $j$, o numero padroni- 
FORATTINI, O.P. et al. Observações sobre atividade de mosquitos Culicidae, em mata resid. al no Vale do Ribeira, S. Paulo, Brasil, Rev. Saúde públ., S. Paulo, 15:557-86, 1981.

T A B E L A 1

Distribuição relativa do número de capturas $(\%)$ realizadas nos intervalos crep para os crepúsculos, respertino (CV) e matutino (CM).

\begin{tabular}{|c|c|c|c|}
\hline \multicolumn{2}{|c|}{ Intervalos creps } & \multirow{2}{*}{$\frac{\mathrm{CV}}{0,91}$} & \multirow{2}{*}{$\frac{\mathrm{CM}}{\mathbf{0 , 5 0}}$} \\
\hline$-5,00$ & $1--4,00$ & & \\
\hline$-4,00$ & $-3,00$ & 3,41 & 3,75 \\
\hline-3.00 & $--2,00$ & 4,55 & 2,75 \\
\hline$-2,00$ & $-\quad-1,00$ & 5,91 & 5,75 \\
\hline$-1,00$ & $--0,50$ & 4,55 & 4,25 \\
\hline$-0,50$ & $1-\ldots$ & 14,09 & 8,50 \\
\hline 0,00 & $1-$ & 11,36 & 9.75 \\
\hline 0,25 & $1-$ & 10,91 & 10.75 \\
\hline 0,50 & $1-\cdots$ & 12,73 & 12,25 \\
\hline 0,75 & - & 8,86 & 11,00 \\
\hline 1,00 & - & 5,00 & 12,50 \\
\hline 1.50 & $1-$ & 4,77 & 3,75 \\
\hline 2,00 & - - & 4,55 & 6,75 \\
\hline 3,00 & $1-\infty$ & 4,32 & 3,25 \\
\hline 4.00 & $1-$ & 3,64 & 3,50 \\
\hline 5,00 & $1-$ & 0,45 & 1,00 \\
\hline & Total & 100,01 & 100,0 \\
\hline & $\mathrm{N}$ & 44 & 40 \\
\hline
\end{tabular}

$\mathrm{N}$ - número de capturas.

zado por intervalo de 5,0 min. e por capturados foi dado pela seguinte fórmula:

$$
X_{e, i . j}^{\prime}=\frac{X_{e, i, j}}{2 h_{i}}
$$

onde $h_{i}$ corresponde ao numero de intervalos de 5,0 min. compreendidos dentro do periodo de tempo $i$, operado por dois capturadores que, como foi mencionado, trabalharam constantemente nas coletas com isca humana. Uma vez obtidos esses números padronizados de culicídeos coletados, as correspondentes médias de Williams $\left(X_{w}\right)$ para os intervalos crep foram calculadas de acordo com a fórmula já descrita. Quanto à comparação desses valores de uma mesma espécie, segundo tais intervalos, foi feita igualmente por meio de percentagens com relação à soma total dessas médias.

Houve também interesse em conhecer a dominância. A sua distribuição, temporal e espacial, permitiu a observação de aspectos peculiares de alguns mosquitos, em relação aos demais coletados. Utilizou-se $o$ indice de Barber-Parker para o estudo da dominância interespecífica (d), de acordo com a seguinte fórmula (Southwood ${ }^{30}, 1978$ ):

$$
\mathrm{d}=\frac{\mathrm{N}_{\max }}{\mathrm{N}_{\mathrm{T}}} \times 100
$$

onde $N_{m \alpha .}$ corresponde ao número de mosquitos capturados na espécie mais freqüente - $N_{T}$ o total de coletados para todas as espécies. No presente trabalho, esse indice 
FORATTINI, O.P. et al. Observações sobre atividade de mosquitos Culicidae, em mata residval no Vale do Ribeira, S. Paulo, Brasil, Rev. Saúde públ., S. Paulo, 15:557-86, 1981.

foi ligeiramente modificado, uma vez que $N_{\mathrm{T}}$ não se refere ao total de capturados mas $\sin$ ao conjunto das nove espécies ou grupos genéricos mais freqüentes, como se verá adiante. Foram também calculadas as percentagens de cada um desses nove grupos, e não apenas a da mais frequente, correspondendo pois a várias classificações na escala de dominância. Táis cálculos foram levados a efeito e distribuídos segundo as horas de coletas, os meses e os ambientes intra e extraflorestal.

Como já se referiu, procedeu-se também à realização de coletas mediante o emprego de outros métodos. Para tanto, foram utilizadas armadilhas, tanto automáticas como manuais. Os resultados obtidos com as primeiras, pretende-se apresentá-los em publicação posterior. As outras foram representadas por duas armadilhas tipo Shannon uperando, respectivamente, dentro e fora da mata residual. Durante o período já mencionado ambas operaram simultaneamente quatro vezes por mês, com duas coletas por ocasião da semana em que se procedia à captura com isca humana. Cada uma dessas coletas compreendeu o periodo das 19:00 às 24:00 h embora, por motivos vários, em algumas poucas ocasiões o inicio tenha sido retardado e o fim antecipado. Deve-se mencionar também que a referida simultaneidade, para os dois mencionados ambientes, tornou-se efetiva somente a partir de março de 1978, tendo operado antes dessa data apenas a armadilha situada dentro da mata. As Figuras 1, 6 e 7 mostram a localização e o aspecto desses dispositivos, tanto no ambiente florestal como no aberto. Também neste tipo de coletas os espécimens foram agrupados por hora de captura.

Quanto à identificação especifica apresentaram-se, para os vários gêneros, as já conhecidas dificuldades inerentes aos exemplares femininos. Isso ocorreu particularmente me relação a Culex (Culex) onde foi possivel identificar, com alguma segurança, apenas reduzido número de espécimens. Todavia, para o subgênero Melanoconion pôde-se adquirir maiores conhecimentos,

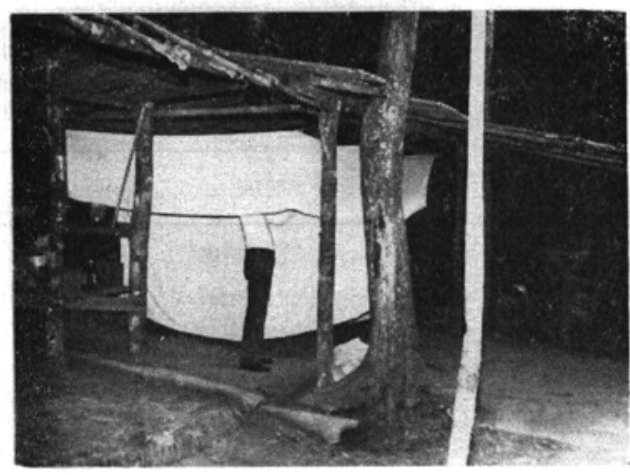

Fig. 6 - Armadilha tipo Shannon localizada dentro da mata residual.

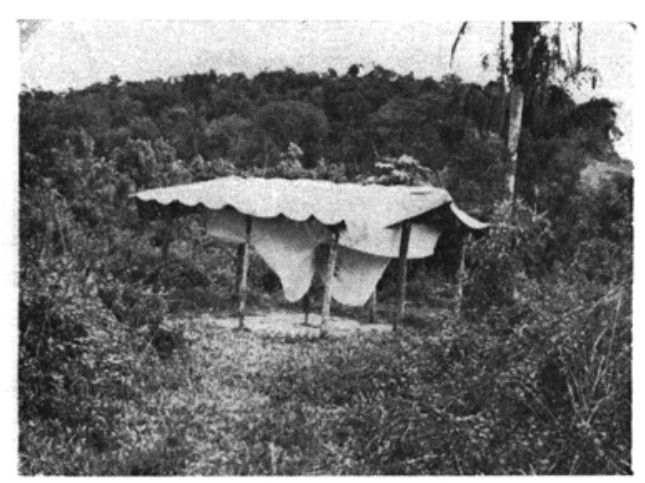

Fig. 7 - Armatilha tipo Shannon localizada em local aberto

mercê do encontro de exemplares masculinos permitindo algumas associações com as fêmeas capturadas. Ainda em relação a esse grupo, pôde-se contar com conhecimentos mais detalhados divulgados recentemente (Sirivanakarn e Belkin 29, 1980). Assim, pois, tornou-se viável identificar duas espécies, representadas por Culex (Melano(onion) crybda e $C x$. (Mel.) vomerifer. Contudo restou ainda apreciável contingente desse subgênero sem identificação específica e que foi rotulado como Culex (Melanoconion) sp., em que pesem terem sido encontradas evidências que fizeram supor da presença, entre outras, de $C x$. evansae, $C x$. intrincatus, $C x$. misionensis, $C x$. oedipus, $C x$. pedroi, $C x$. pilosus e $C x$. plectoporpe. 
FORATTINI, O.P. et al. Observaçoes sobre atividade de mosquitos Culicidae, em mata residual no Vale do Ribeira, S. Paulo, Brasil, Rev. Saúde públ., S. Paulo, 15:557-86, 1981.

Em relação a Mansonia (Mansonia) caminhou-se em direção inversa, pois chegou-se à conclusão da impossibilidade momentânea de separação de seus membros. Assim sendo, admitiu-se reunir nesse grupo, mosquitos muito provavelmente representantes de Ma. indubitans, Ma. pseudotitillans, Ma. titillans e Ma. wilsoni. No que concerne a Psorophora, o que foi anteriormente considerado (Forattini e col. ${ }^{7}, 1978$ ) como conjunto de $P$ s. albipes e PS. lutzii, pôde-se separar no sentido de ser constituido, em sua maioria, por representantes de $P s$. albigenu e, em menor número, por espécimens da segunda daquelas duas espécies. Quanto aos sabetíneos, da presença mais significante do gênero Phoniomyia, foi possivel distinguir apenas $P h$. davisi, mesmo assim admitindo que exemplares dessa espécie tenham participado do conjunto idenficado somente a nível de gênero. Em vista disso, os resultados relatados representam dados computados para o grupo genérico Phoniomyia sp. Finalmente, deve-se mencionar que a disposição sistemática e a grafia obedeceram aos catálogos e listas de abreviaturas publicados recentemente (Reinert 26 1975; Knight e Stone ${ }^{18}$ 1977; Knight ${ }^{17}$ 1978).

Adotou-se a orientação de considerar os culicideos que, individualmente, participaram com percentuais de, pelo menos, $1,0 \%$ do total geral obtido no respectivo tipo de coleta. Os demais tiveram a ocorrência assinalada, como registro de sua presença na composição faunística local. Tal critério foi aplicado para os identificados até o nível de espécie. Quanto aos apenas agrupados em gêneros ou subgêneros, foram considerados os que compareceram com percentual minimo correspondente a $5,0 \%$ do total geral conseguido na modalidade de captura empregada.

\section{RESULTADOS}

No mencionado período, compreendido entre janeiro de 1978 e março de 1980 , as coletas levadas a efeito com a utilização de isca humana e de armadilhas tipo Shannon, estas instaladas no interior da mata e no aberto, forneceram o total global de 115.684 mosquitos. A distribuição específica, de acordo com os critérios já descritos, consta das Tabelas 2 e 3 . Pode-se verificar que 17 espécies ou grupos genéricos representaram mais de $90,0 \%$ do material coletado. $O$ restante distribuiu-se entre 71 dessas categorias, segundo o tipo de captura realizado. Analisando-se os dados relativos aos primeiros (Tabela 2), observou-se variação quanto à representatividade de acordo com as modalidades de coleta. Alguns compareceram em todas, enquanto outras deixaram de o fazer para uma ou duas, das três utilizadas. Assim sendo, no estudo do comportamento houve necessidade de outra seleção, além da já levada a efeito quanto ao número de espécimens que compareceram no cômputo geral.

Desde que se objetivou observar a atividade em relação à isca humana, as atenções convergiram sobre os culicídeos que se apresentaram de maneira expressiva nos três tipos de captura. Além disso, e levando-se em conta que as armadilhas de Shannon somente foram operadas no período noturno, tornou-se necessário incluir os dados referentes a culicídeos diurnos que compareceram na isca humana. Tal foi o caso de Phoniomyia sp. (incluindo $P h$. davisi) e dos representantes de Psorophora. Em relação a estes, o isolamento do virus Rocio a partir de espécimens de Ps. ferox, fato recentemente relatado, resultou em particular interesse quanto a esse mosquito (Lopes e col.20, 1981). No que concerne aos outros que foram coletados sobre 0 homem, sua representatividade no cômputo geral foi muito pequena, motivo pelo qual deixaram de ser considerados. Dessa maneira, os mosquitos cujo comportamento será focalizado nas linhas que seguem, representaram o conjunto de $77,8 \%$ do total de espécimens coletados. 


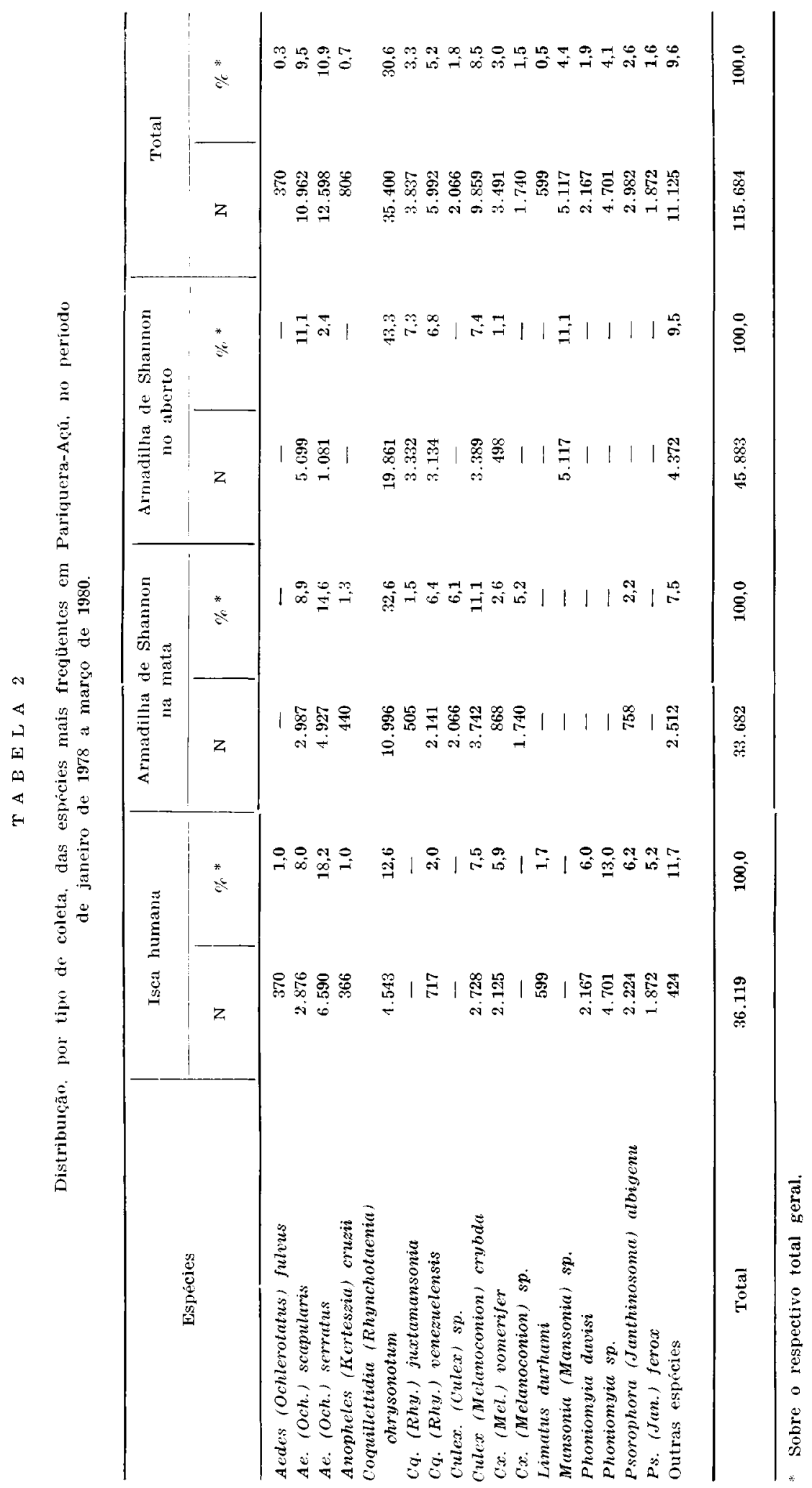




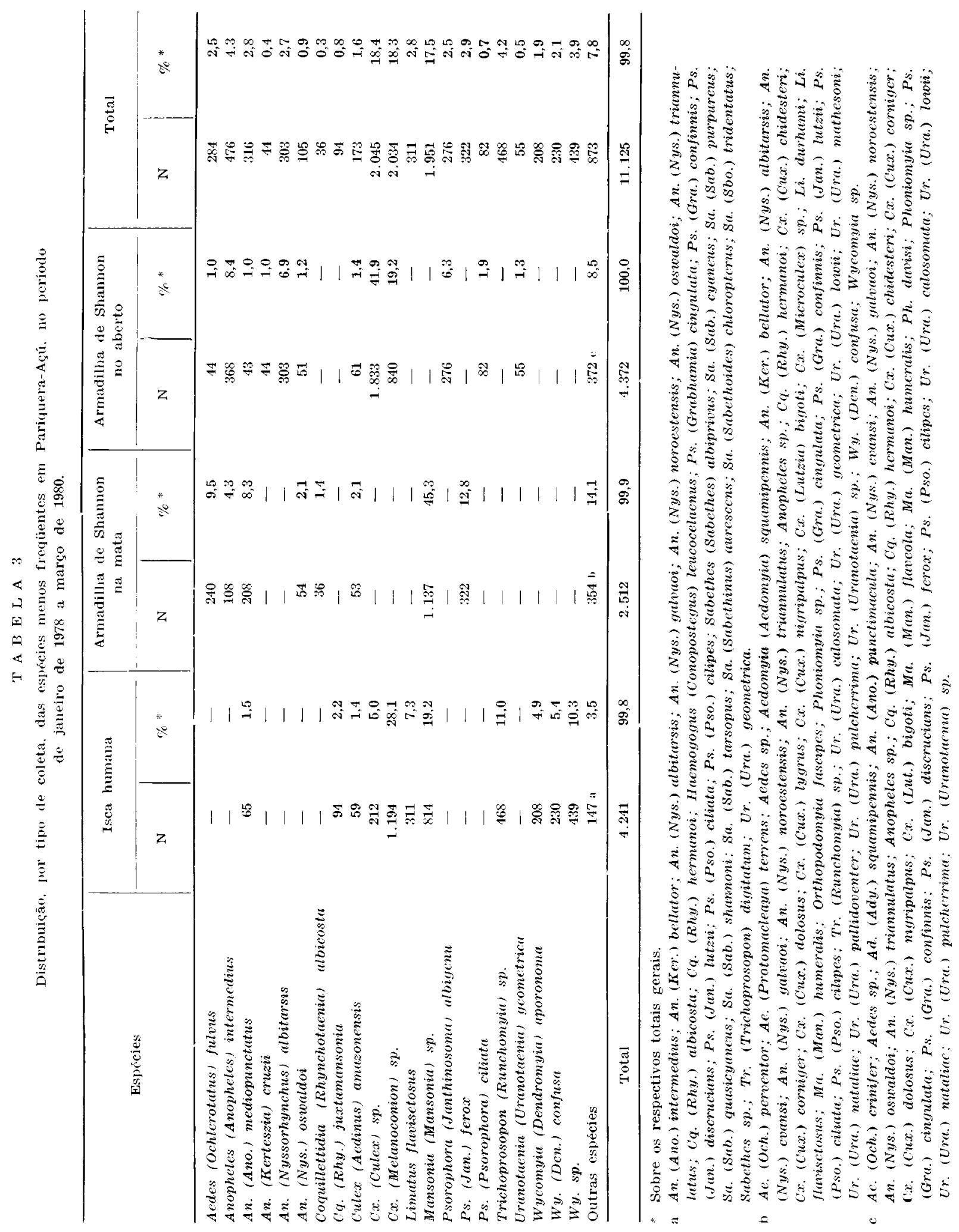


FORATTINI, O.P. et al. Observações sobre atividade de mosquitos Culicidae, em mata residual no Vale do Ribeira. S. Paulo, Brasil, Rev. Saúde pübl., S. Paulo, 15:557-86, 1981.

Atividades horárias - Na Tabela 4 en. contram-se expostos, por intervalos horários, os resultados conseguidos com as capturas bimensais em isca humana, de $25 \mathrm{~h}$ consecutivas de duração. Foram assim levadas a efeito 54 dessas coletas, obtendo-se 30.543 dos mosquitos mais freqüentes.

Inicialmente, pôde-se observar a atividade predominantemente diurna de Psorophora albigenu, Ps. ferox e de Phoniomyia sp., em contraste com a essencialmente noturna de Coquillettidia chrysonotum, Cq. venezuelensis, Culex crybda e $C x$. vomerifer. Tais aspectos ressaltam nos gráficos apresentados na Figura 8. Por sua vez, Aedes scapularis e Ae. serratus não revelaram qualquer acentuada inatividade, embora apresentassem diminuição no comparecimento noturno, em especial modo na segunda metade desse periodo. Quanto ao "efeito de intrução", pôde-se observá-lo para os mosquitos diurnos, comparando-se as médias registradas nos dois intervalos, inicial e final, correspondentes aos horários das 10:00 às 11:00 horas.

Os resultados obtidos nas coletas com as duas armadilhas tipo Shannon acham-se expostos na Tabela 5. Pôde-se verificar que, no periodo das $19: 00$ às $24: 00 \mathrm{~h}$ correspondente, grosso modo, à primeira metade da noite, em ambas deixaram de comparecer os representantes de Phoniomyia sp. Por sua vez, as médias da primeira hora, ou seja, das 19:00 às 20:00 h, mostraram-se a maioria das vezes superiores às das horas seguintes. Notou-se também a ausência do Ps. albigenu no aberto, bem como menor frequiência do Ae, serratus nesse local em relação às coletas efetuadas na mata. Por outro lado, Ae. scapularis mostrou-se ativo nos dois ambientes, sem alteração apreciável de suas médias.

Atividades crepusculares e pericrepusculares - Mediante o emprego de técnica já mencionada, foi possivel o estudo do comportamento por ocasião de 84 intervalos crepusculares, dos quais 44 vespertinos e 40 matutinos (Tabela 1). A duração desses períodos variou de 21 a 29 min. Considerando esse espaço de tempo como sendo valor de uma unidade crep, como se viu o intervalo crepuscular correspondeu ao de $0,0-1,0$ para o vespertino e de $1,0-0,0$ para 0 matutino. Dessa forma a variação do crep, em minutos, foi a seguinte:
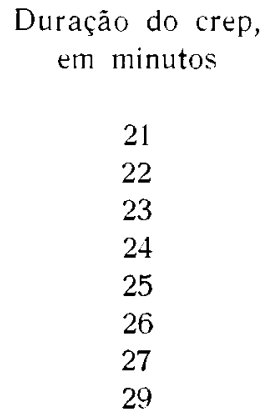

Quanto aos horários do inicio, variaram de acordo com a época do ano. Para o crepúsculo vespertino o mais precoce ocorreu às 17:29', em junho, e o mais tardio às 19:07', em janeiro. Para o matutino esses
Número de crepúsculos vespertinos

\begin{abstract}
Número de crepúsculos matutinos
\end{abstract}

$\begin{array}{rrr}21 & - & 1 \\ 22 & 3 & 4 \\ 23 & 11 & 10 \\ 24 & 15 & 10 \\ 25 & 12 & 12 \\ 26 & 1 & - \\ 27 & 2 & 2 \\ 29 & - & 1 \\ & - & 40\end{array}$

eventos corresponderam às $04: 48^{\prime}$ em dezembro e às 06:31' em julho. Tais variaçōes, correspondentes aos dias de coletas, acham-se representadas no gráfico da Figura 9. 

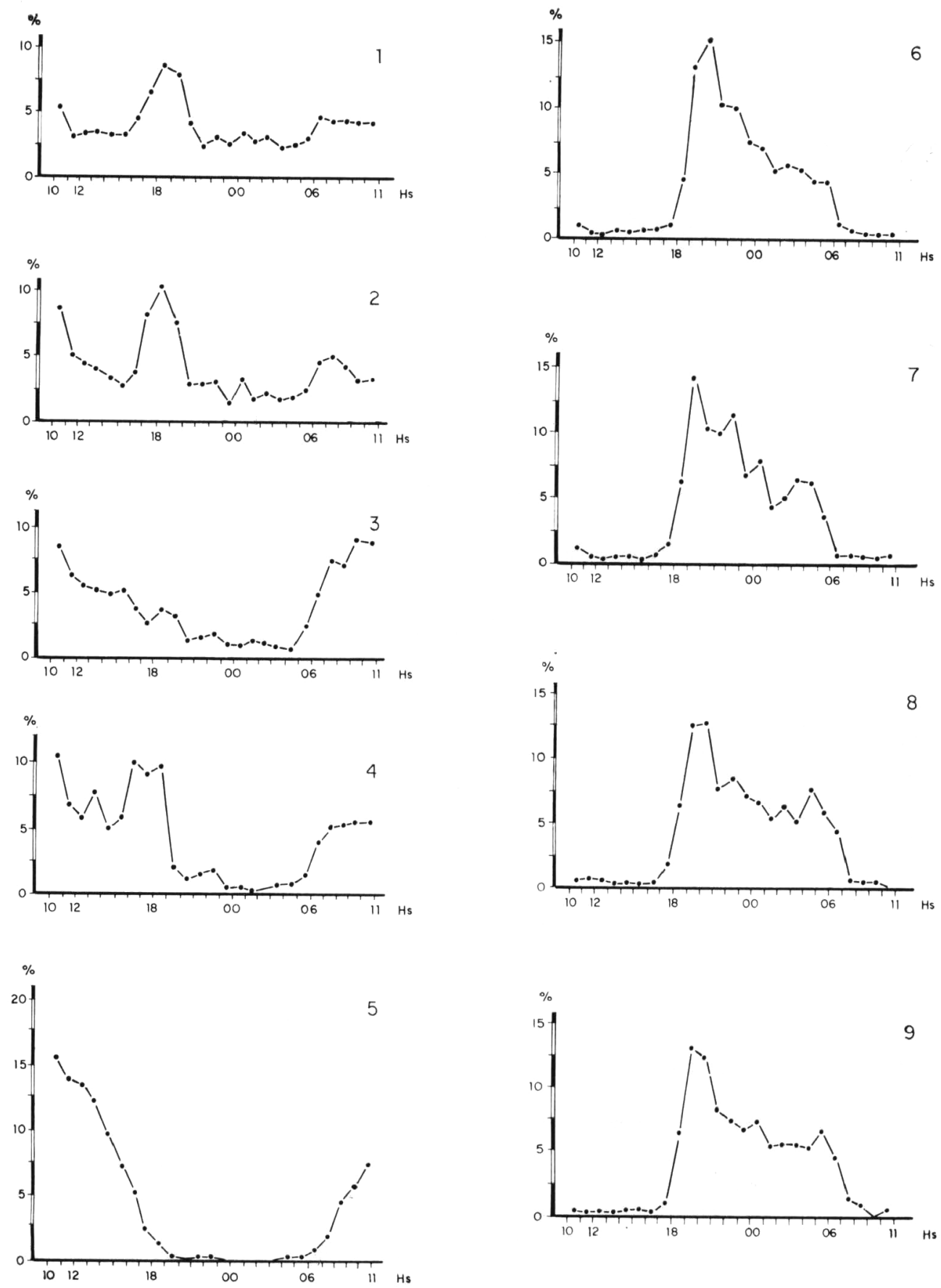

Fig. 8 - Atividade horária das espécies mais freqüentes, observada em mata residual de Pariquera-Açú. Distribuição das médias, consideradas em percentagens, obtidas mediante coletas ininterruptas de 25 horas com isca humana, no período de janeiro de 1978 a março de 1980. 1 - Aedes scapularis. 2 - Ae. serratus. 3 - Psorophora albigenu. 4 - Ps. ferox. 5 - Phoniomyia sp. 6 - Coquillettidia chrysonotum. 7 Cq. venezuelensis. 8 - Culex orybda. 9 - Cx. vomerifer. Hs - horas. \% - valores percentuais das médias de Williams $\left(\mathrm{X}_{w}\right)$. 
FORATTINI, O.P. et al. Observações sobre atividade de mosquitos Culicidae, em mata residual no Vale do Ribeira, S. Paulo, Brasil, Rev. Saúde públ., S. Paulo, 15:557-86, 1981.

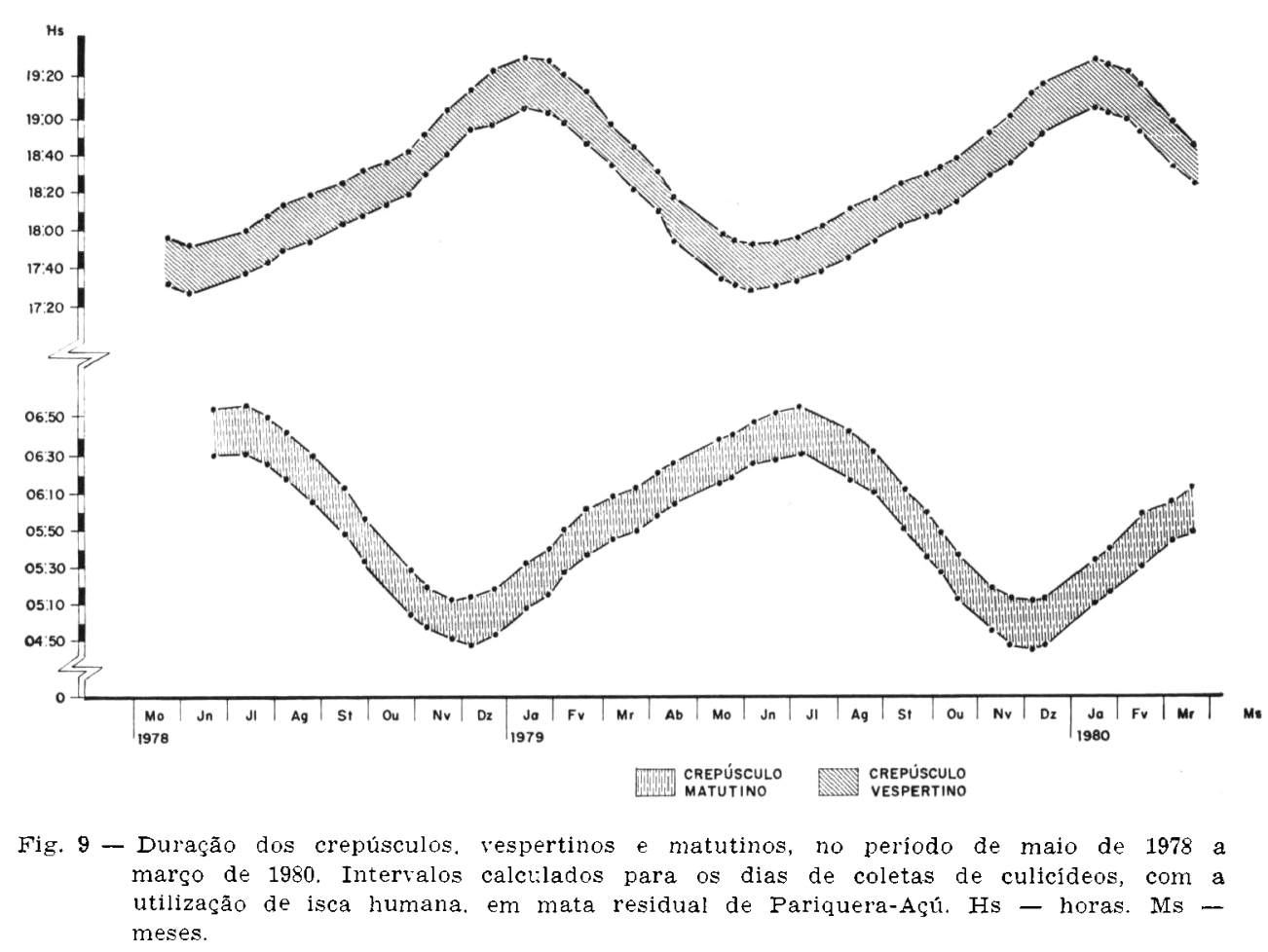

Como se mencionou, os mosquitos capturados nesses intervalos, a espaços de 5,0 min, forneceram dados que foram distribuidos em função de unidades crep. Dessa maneira, destacaram-se os resultados correspondentes aos crepúsculos, vespertino e matutino, referentes aos creps $0,0-1,0$ e $1,0-0,0$, respectivamente. Assim procedendo, obteve-se a distribuição das médias $\bar{X}_{w}$, consideradas em percentagens, como o representado pelos gráficos das Figuras 10 e 11 . Obteve-se também os valores referentes aos creps antecedentes e sucessivos. Entre as espécies predominantemente diurnas (Figura 10), pôde-se observar a ocorrência de estímulo que se revelou como elevação acentuada da atividade por ocasião do crepúsculo v'espertino, em Ae. scapularis e Ps. albigenu. O mesmo se observou, para esses mosquitos, embora sem pico pronunciado, por ocasião do intervalo crepuscular matutino. Por sua vez, Ae. serratus e Ps. ferox não revelaram essa possivel influência vespertina, observando-se apenas a ocorrência de incremento à partir do equivalente periodo matutino. Em vários pontos dos gráficos ocorrem aspectos que sugerem algum comportamento antagônico dessas duas últimas espécies em relação às duas primeiras. Quanto a Phoniomyia sp., seu comportamento essencialmente diurno revela-se pelo aspecto nitidamente interruptor da atividade, que parecem desempenhar ambos os intervalos crespusculares. No que concerne aos mosquitos noturnos (Fig. 11) tais periodos assinalam, respectivamente, a intensificação e o decréscimo da atividade, podendo ocorrer algum pico logo após o fim de ambos os crepúsculos. 

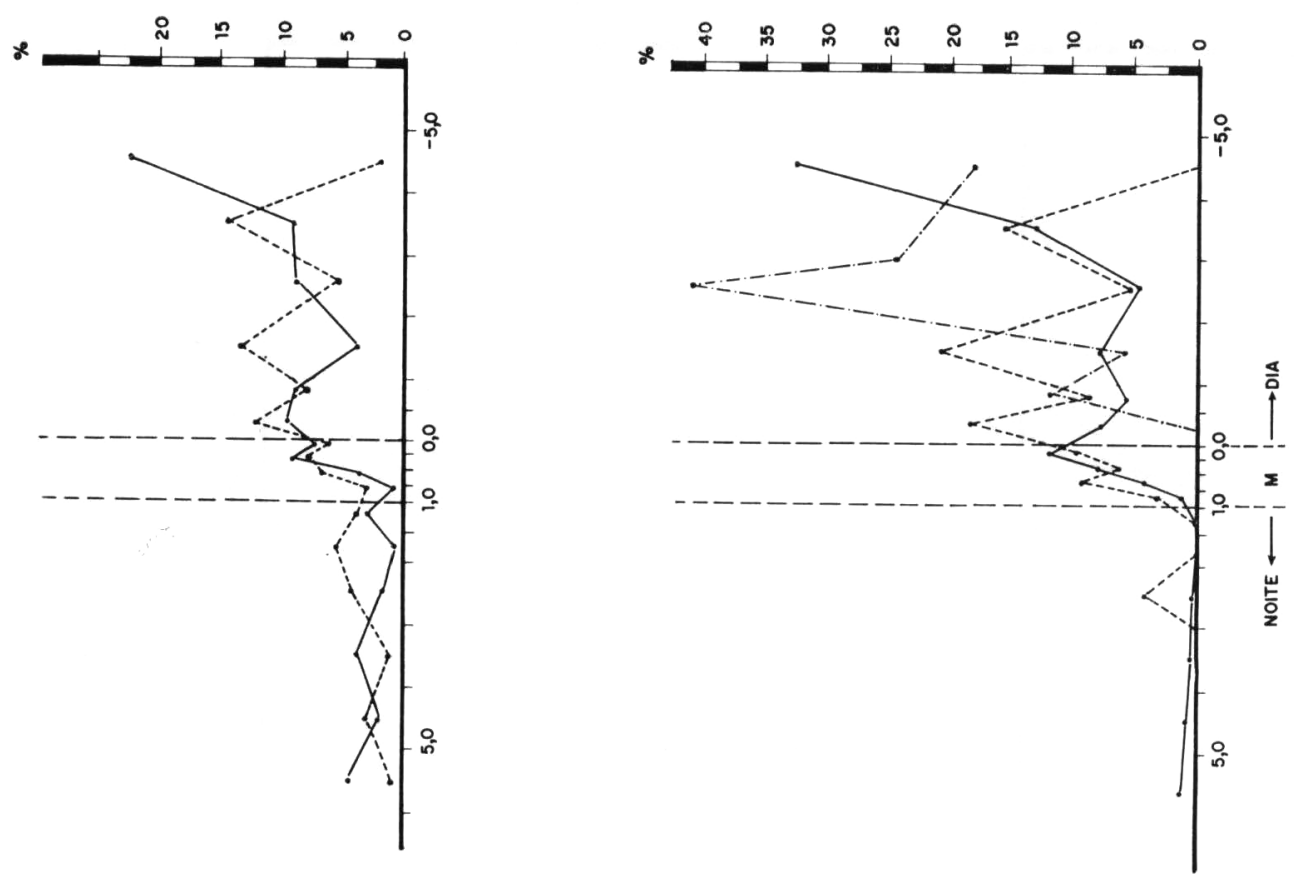

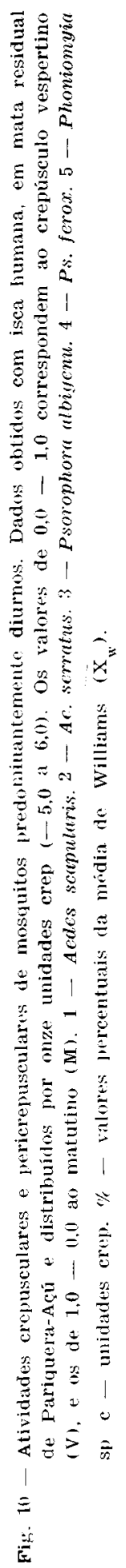



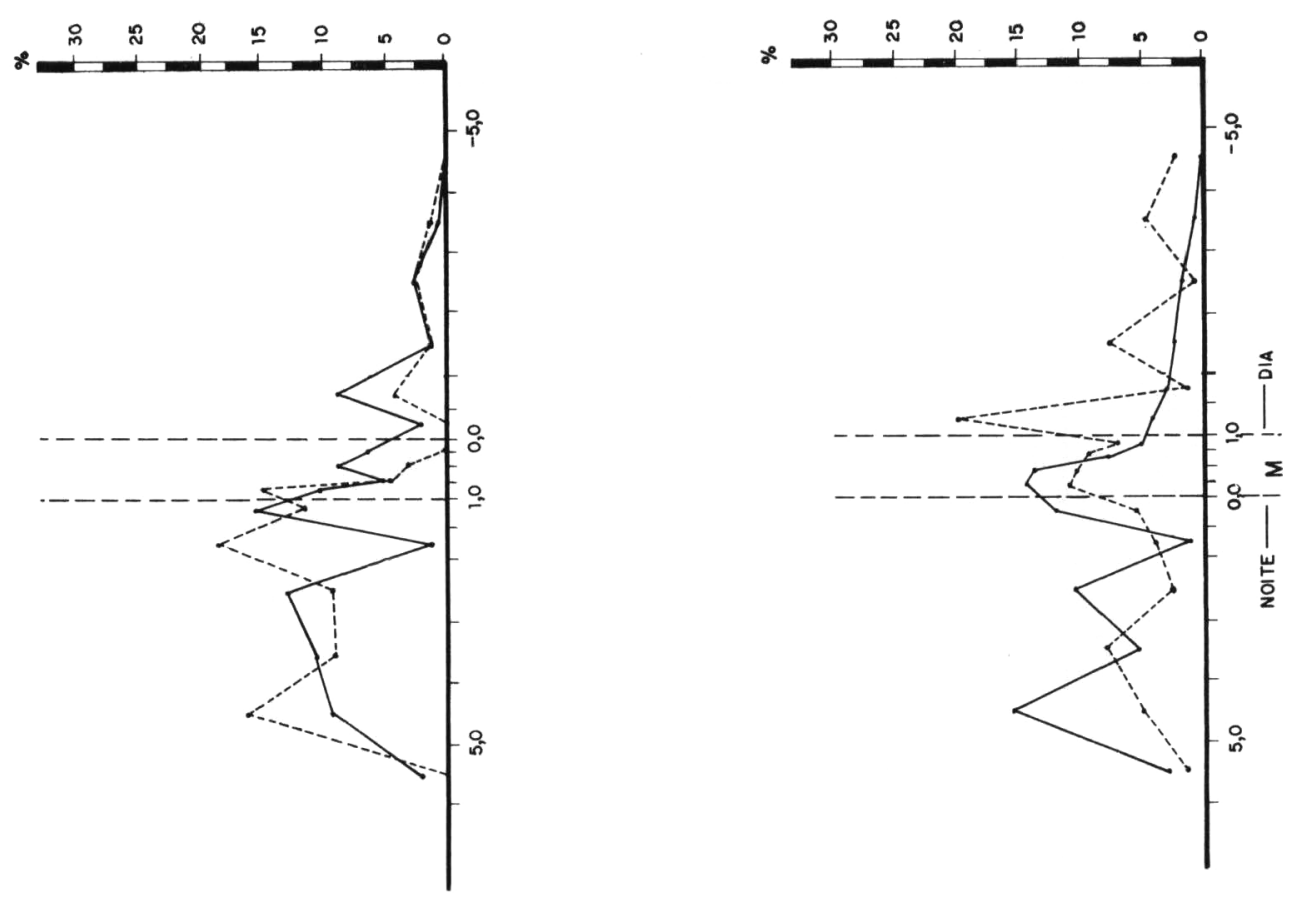

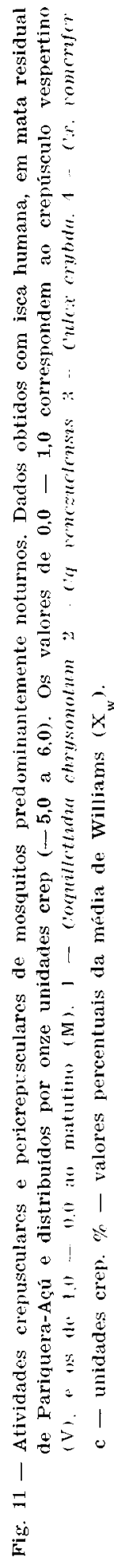
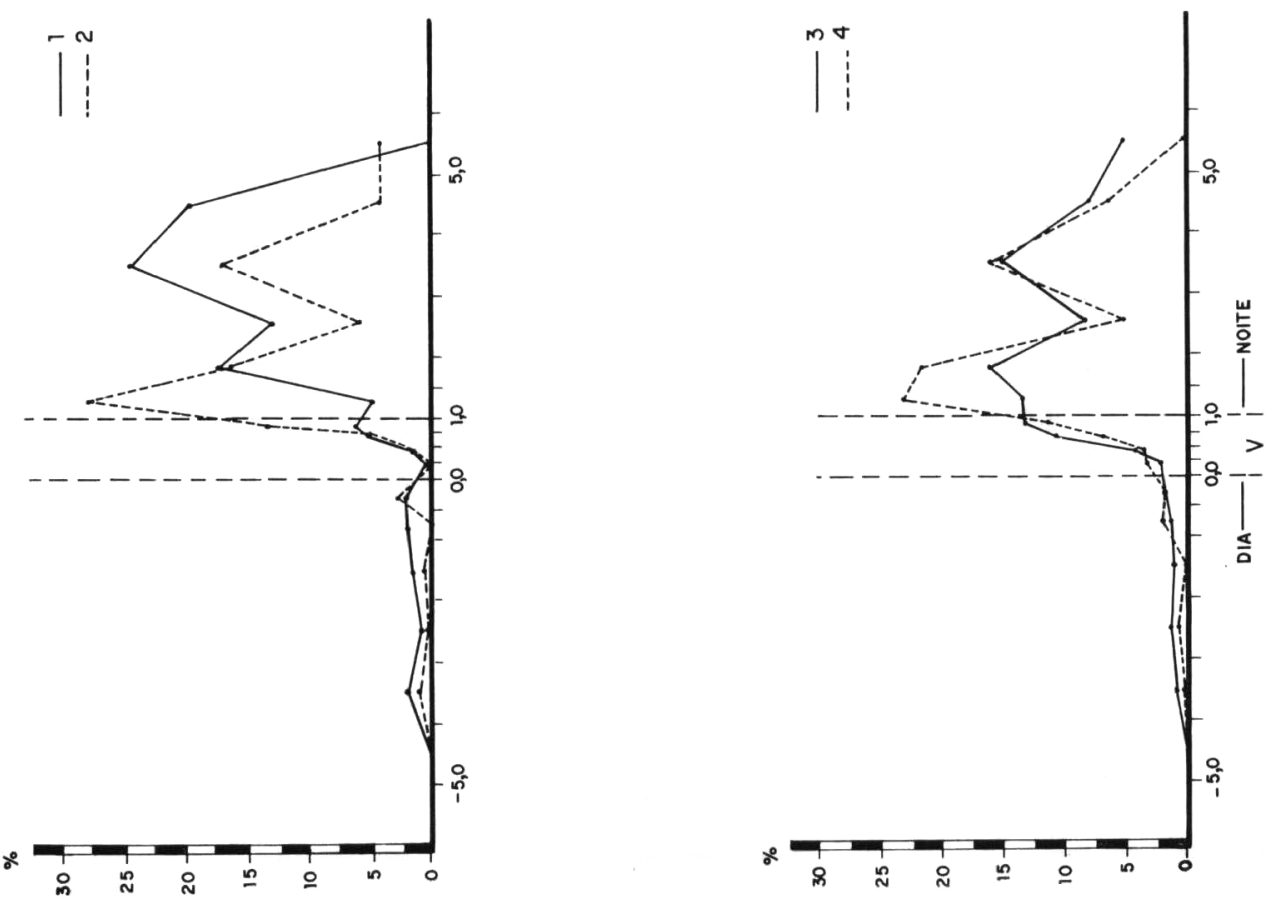
FORATTINI, O.P. et al. Observações sobre atividade de mosquitos Culicidae, em mata residual no Vale do Ribeira, S. Paulo, Brasil, Rev. Saúde públ., S. Paulo, 15:557-86, 1981.

Dominância e variação sazonal - Considerando os percentuais de comparecimento nas coletas, sobre o total referente às nove espécies ou grupos mais freqüentes, obteve-

\begin{tabular}{lc}
\multicolumn{1}{c}{ Espécies } & \multicolumn{1}{c}{ Isca } \\
humana
\end{tabular}

Todavia, esses aspectos gerais por si sós não traduzem o comportamento no tempo $\mathrm{e}$ no espaço, uma vez que, como se viu em parágrafos anteriores, incluem mosquitos com variações acentuadas relativas aos períodos diurnos e noturnos. Parecem representar exceção, a essa regra, os Aedes scapularis e Ae. serratus uma vez que sua ocorrência, embora com oscilações, se manteve nesses dois periodos (Fig. 8). Assim sendo, procedeu-se à distribuiçăo dos indices referentes a essas duas espécies, nos três tipos de coletas, tanto nos intervalos horários como nos mensais. Os gráficos da Figura 12 mostram a distribuição horária dessas dominâncias tendo sido excluidas as referentes à primeira hora, das 10:00 às 11:00, das capturas com isca humana, em virtude da ocorrência do já mencionado "efeito de intrusão". Pôde-se assim observar a estabilidade geral do comportamento dos dois culicídeos, no que concerne aos dados obtidos dentro da floresta residuária, representados pelos resultados com a isca humana e com a armadilha tipo Shannon ali operada (Figura 11, AB). Quanto aos conseguidos na área aberta mediante o emprego da segunda dessas técnicas, permitiram evidenciar acentuada queda na parti- -se para cada um as proporções ou indices de Barber-Parker. De acordo com o tipo de coleta, os resultados globais $(\%)$ foram os seguintes:

\begin{tabular}{|c|c|c|}
\hline $\begin{array}{l}\text { Armadilha } \\
\text { na mata }\end{array}$ & de & $\begin{array}{l}\text { Shannon } \\
\text { no aberto }\end{array}$ \\
\hline 11,2 & & 15,4 \\
\hline 18,4 & & 3,3 \\
\hline 41,1 & & 60,1 \\
\hline 8,0 & & 9,5 \\
\hline 13,1 & & 10,2 \\
\hline 3,2 & & 1,5 \\
\hline- & & - \\
\hline 2,8 & & - \\
\hline 1,2 & & - \\
\hline 99,0 & & 100,0 \\
\hline
\end{tabular}

cipação de Aedes serratus, enquanto o mesmo não ocorreu com Ae. scapularis que manteve presença comparável à observada no interior da mata residual (Figura $12 \mathrm{C}$ ). Por sua vez, a distribuição mensal desses índices, representada pelos gráficos da Figura 13, permitiu verificar o mesmo aspecto, ou seja, a dominância de $A e$. serratus sobre o Ae. scapularis, no ambiente intraflorestal e deste sobre aquele no extraflorestal. Todavia é de se notar a exceção a essa regra no período correspondente ao mês de junho. Assim é que pôde-se observar, nessa oportunidade e para os três tipos de coletas, o sensivel predomínio do Ae. scapularis sobre Ae. serratus, mesmo no interior da mata residual.

A distribuição mensal das médias $\overline{\mathrm{X}}_{\mathrm{w}}$ obtidas nas capturas com isca humana forneceu, para as espécies mais freqüentes, os gráficos constantes da Figura 14. Como se pode verificar pela sua análise, houve geral tendência à diminuição correspondente ao período do ano referente aos meses com menores niveis de temperatura e pluviosidade, ou seja, de maio a agosto. Como exceção, assinalou-se o comportamento de Ae. scapularis com sensivel pico no mês de junho, acompanhando, como se mencio- 

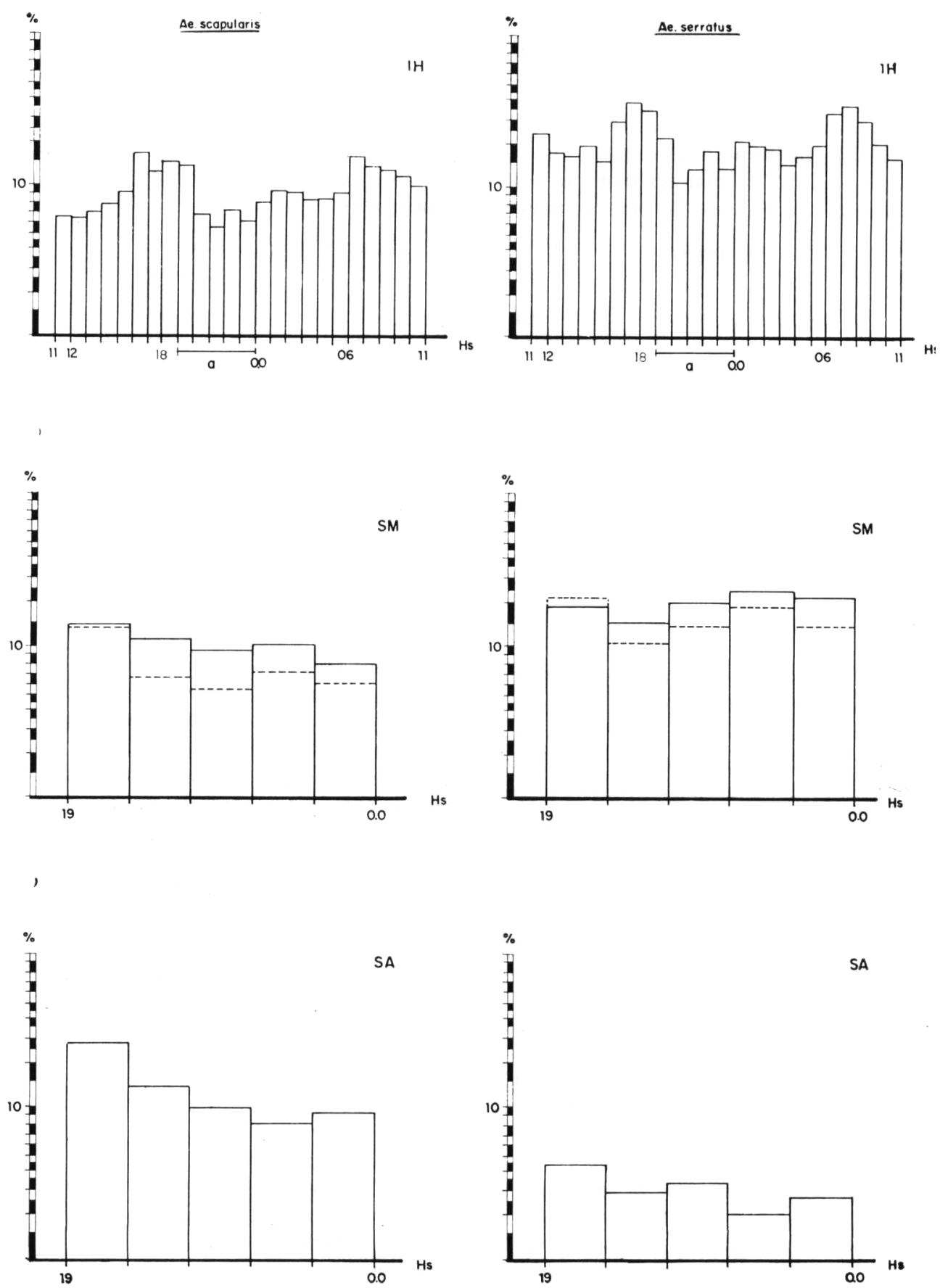

Fig. 12 - Distribuição horária da domináncia (índices de Barber-Parker) de Aedes scapularts e de Ae. serratus, em Pariquera-Açú. Coletas com isca humana (IH) durante 24 horas, e com armadilhas tipo Shannon operadas no interior da mata residual (SM) e no aberto (SA) obedecendo ambas, simultaneamente, ao horário das 19:00 às 24:00 h. Nos gráficos correspondentes a SM estão representados os valores obtidos em relação às mesmas horas (a), nas capturas IH. a - período das 19:00 às 24:00 h. com IH. Hs - horas. \% - indices de Barber-Parker. 
FORATTINI, O.P. et al. Observaçóes sobre atividade de mosquitos Culicidae, em mata residral no Vale do Ribeira, S. Paulo, Brasil, Rev. Saúde públ., S. Paulo, 15:557-86, 1981.

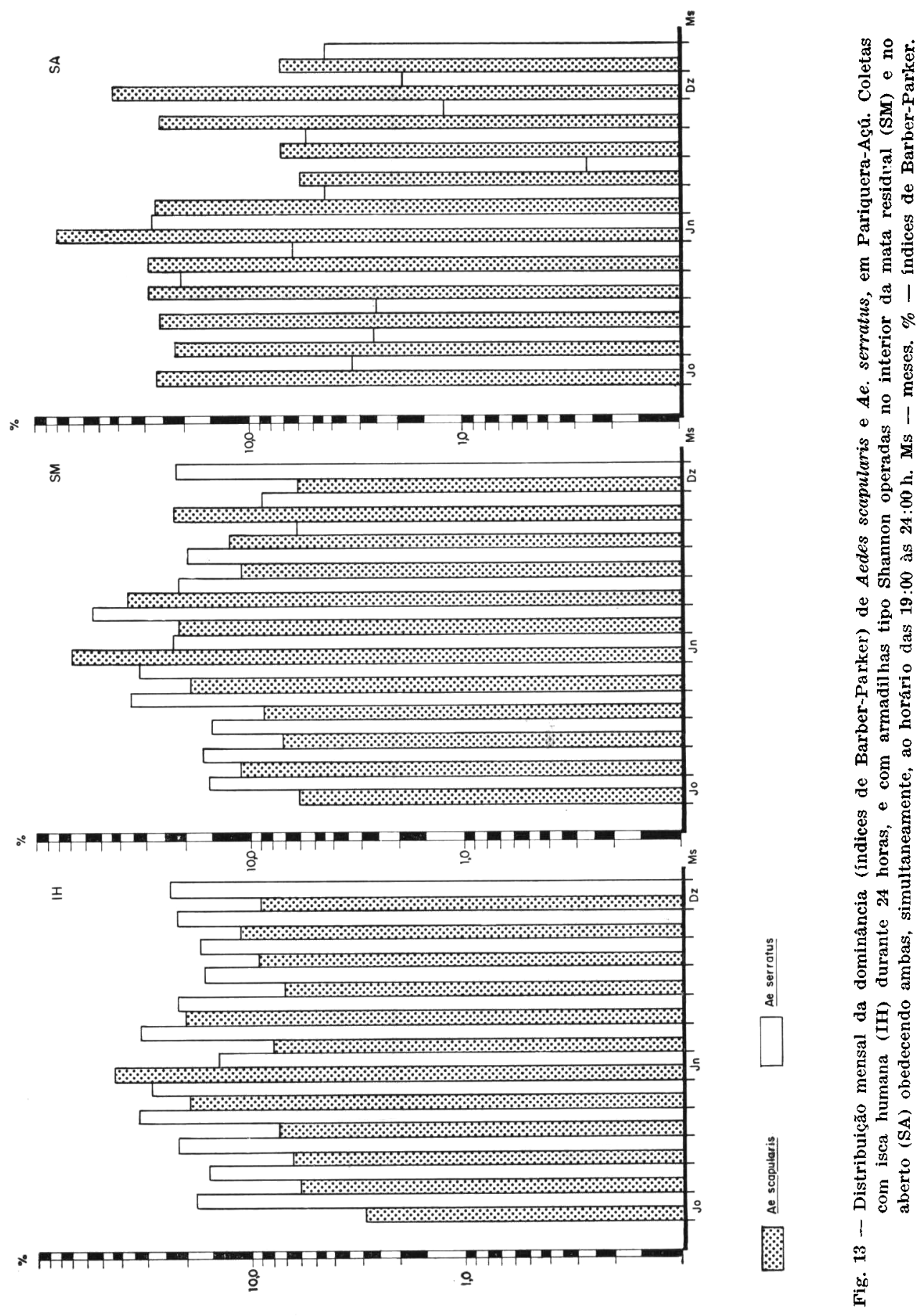



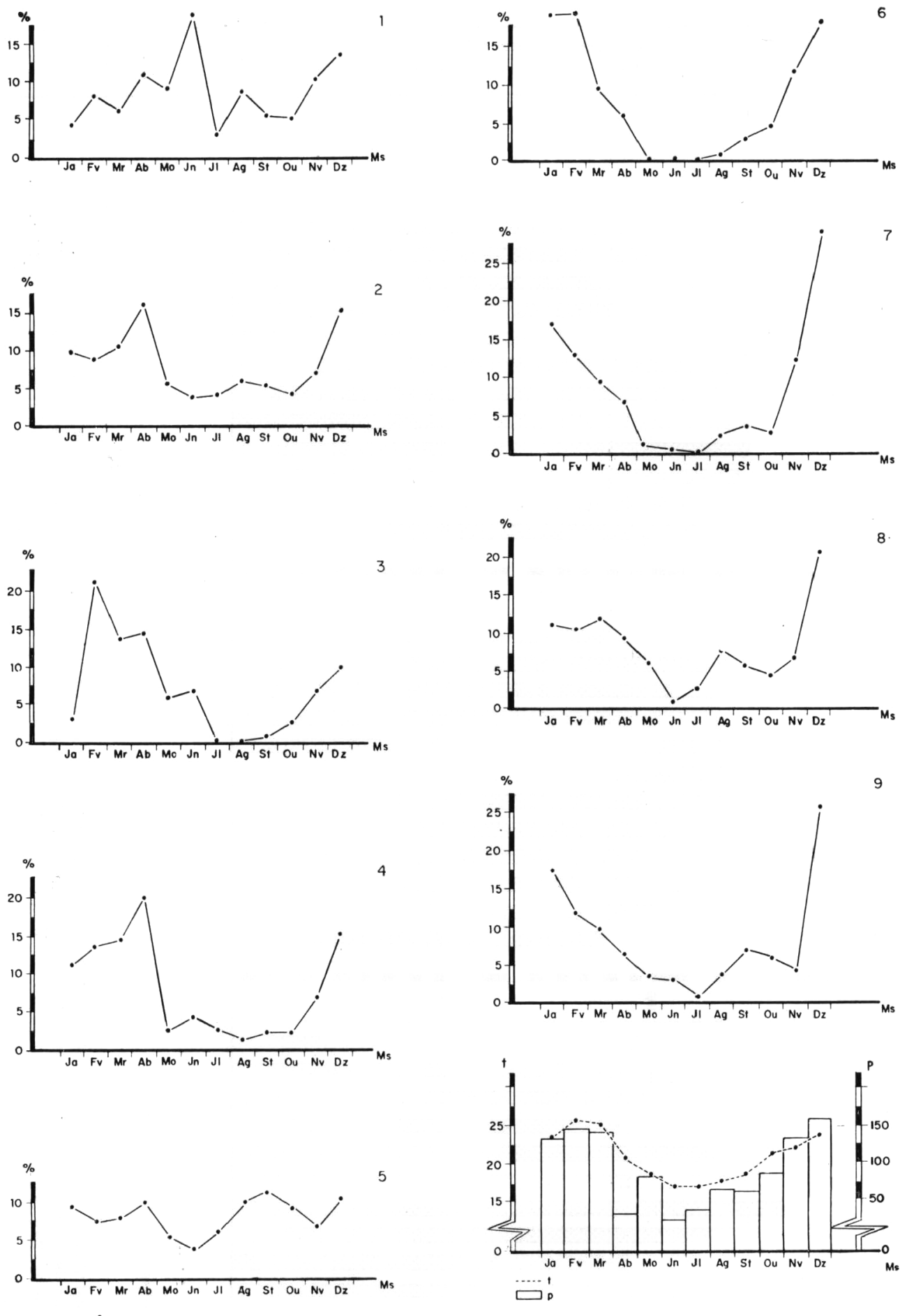

Fig. 14 - Variação mensal das médias, consideradas em percentagens, relativas às espécies mais frequentes, e obtidas com isca humana, em mata residial de Pariquera-Açú, no período de janeiro de 1978 a março de 1980. 1 - Aedes scapularis. 2 - Ae. serratus. 3 - Psorophora albigenu. 4 - Ps. ferox. 5 - Phoniomyia sp. 6 - Coquillettidia chrysonotum. 7 - Cq. venezuelensis. 8 - Culex crybda. 9 - Cx. vomerifer. Ms meses. p. precipitaçōes médias mensais. $t$ - temperaturas médias mensais. \% valores percentuais das médias de williams $\left(\overline{\mathrm{X}}_{\mathrm{w}}\right)$. 
FORATTINI, O.P. et al. Observaçoes sobre atividade de mosquitos Culicidae, em mata residual no Vale do Ribeira, S. Paulo, Brasil, Rev. Saúde públ., S. Paulo, 15:557-86, 1981.

nou, a dominância essa época. Além disso, observou-se, tanto para essa espécie como para Ae. serratus e Phoniomyia sp., flutuaçōes menos acentuadas do que para os demais. Eis que, em nenhum mês esses mosquitos atingiram niveis minimos de comparecimento que fossem comparáveis com os observados para as outras espécies, algumas das quais chegaram mesmo a desaparecer das coletas, nessas oportunidades.

\section{COMENTARIOS}

De maneira geral, para algumas das várias espécies focalizadas neste trabalho, os ritmos nictemerais confirmaram os observados em outras áreas neotropicais (Galindo e col. ${ }^{9}$ 1966; Aitken e col.2 1968; Kruijf 19 1972; Degallier e col. ${ }^{6}$ 1978. Assim, pois, o caráter essencialmente noturno de Coquillettidia venezuelensis, Culex crybda e $C x$. vomerifer, parece ser feição constante de seu comportamento. O mesmo poder-se-ia dizer de alguns aspectos diurnos como os apresentados por Psorophora ferox e pro Ps. albigenu, esta de maneira menos acentuada do que aquela e assemelhando-se, nesse particular, a $P$ s. albipes de outras regiōes. Ao lado disso, pôde-se registrar discrepancias em relação a Aedes scapularis que, em localidades do Surinam, chega a desaparecer no período noturno. No entanto, nas presentes observações, esse mosquito portou-se de maneira análoga a Ae. serratus o qual, por sua vez, apresentou semelhança do ritmo registrado em Surinam e Trinidad. Caracterizou-se, pois, pela predominància diurna mas com manutenção de apreciável atividade noturna (Aitken e col. ${ }^{2}$ 1968; Kruijf 19 1972).

Considerado cada ciclo de maneira geral, em nenhuma das espécies foi possivel detectar pico destacado no período das 24 horas. Não houve qualquer elevação sensivel que pudesse denotar incremento de atividade, de maneira intensa e de curta duração, com subseqüente manutenção de niveis baixos nas demais horas (Tabela 4, Figura 8). Assim sendo, esses mosquitos poderiam ser inclui- dos, segundo tal critério, no grupo definido por Haddow ${ }^{14}$ (1954) como formado por aqueles cuja atividade se prolonga, pelo menos, por alguma parte do periodo das 24 horas, seja diurna ou noturna. Em poucos casos pode ocorrer a persistência ativa durante todo o tempo do ciclo diário. Este último aspecto é o que parece ter sido apresentado, nestas pesquisas, pelas duas supramencionadas espécies de Aedes. De qualquer maneira, tais caracteristicas de comportamento poderiam indicar alguma feição peculiar, principalmente no que concerne aos possiveis criadouros. Seriam, neste caso, representados geralmente por coleçôes liquidas no solo, de caráter permanente ou semi-permanente, como alagadiços, rios, lagos e açudes. Além disso, podem também indicar a possibilidade desses mosquitos não serem grandemente seletivos quanto ao local de suas atividades, sendo passíveis de apresentar variações regionais que digam respeito às suas preferências quanto a se mostrarem ativos ao nivel do solo ou da copa das árvores, no caso do ambiente florestal. Torna-se assim interessante considerar que, a predominância desse tipo de comportamento na regiāo estudada, concorda com a existência de apreciáveis coleções líquidas locais que poderiam servir de criadouros. E não apenas o rio Jacupiranga e seus afluentes e alagadiços, com os açudes e o próprio pôlder construido artificialmente. Feições análogas puderam ser observadas em relação aos dados obtidos por ocasião da primeira metade da noite, nas coletas com as armadilhas tipo Shannon (Tabela 5). Ao lado da atividade das espécies noturnas, verificou-se também a persistente presença dos dois representantes de Aedes, havendo apenas diferença quanto à situação espacial da captura, como se considerará adiante. É de se notar ainda aqui, a ocorrência de médias mais altas na primeira dessas horas, ou seja, das 19:00 às 20:00. Possivelmente a explicação poderá ser encontrada, seja em algum "efeito de intrusão" seja em estímulo decorrente do crepúsculo vespertino. 


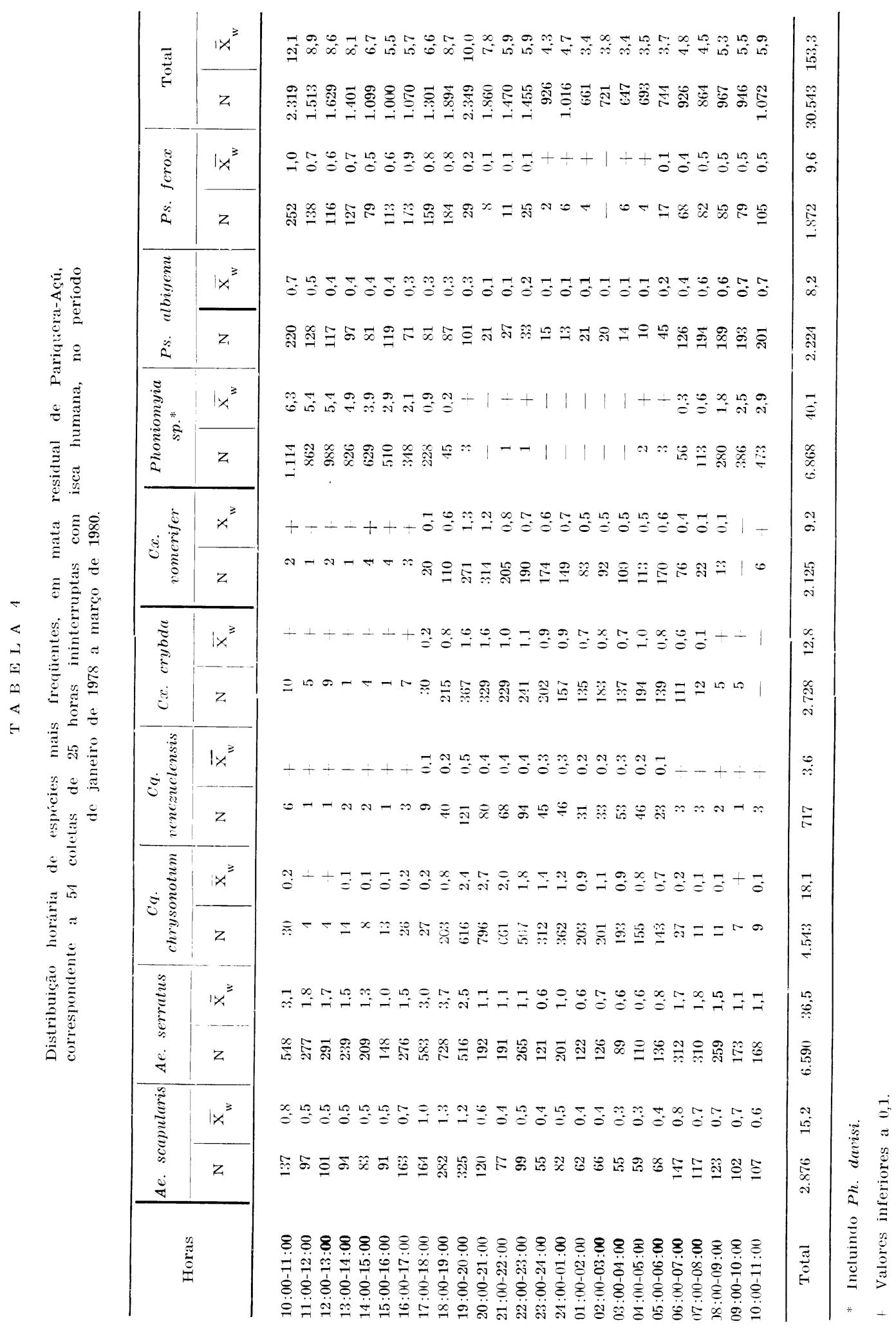




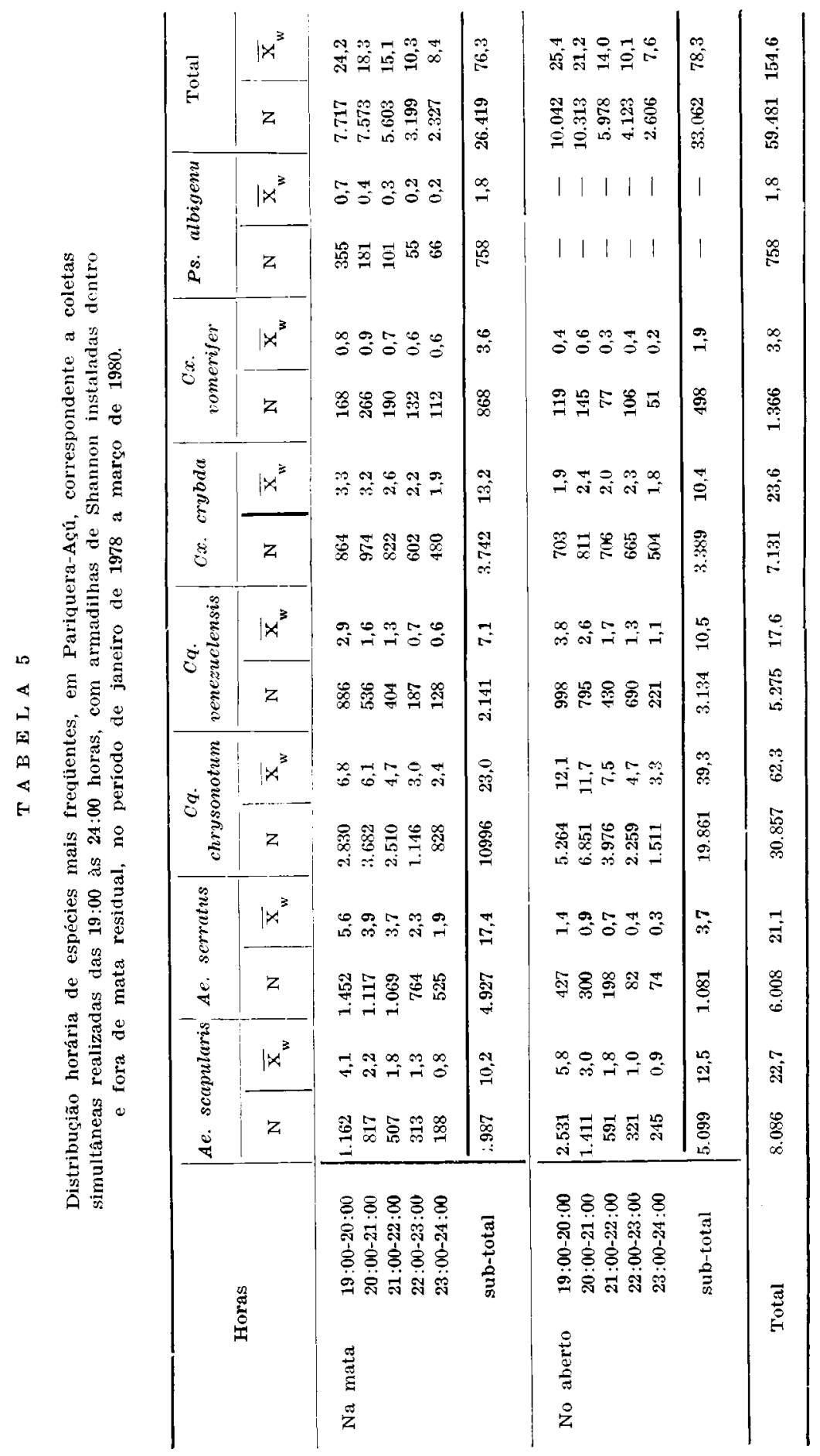


FORATTINI, O.P. et al. Observaçóes sobre atividade de mosquitos Culicidae, em mata residral no Vale do Ribeira, S. Paulo, Brasil, Rev. Saúde pủbl., S. Paulo, 15:557-86, 1981.

Como se mencionou, as pesquisas visando os horários que encerram os intervalos crepusculares, tiveram por objetivo detectar possivel influência das condições peculiares, de luminosidade e de microclima, que ocorrem em tais oportunidades. A ocorrência de periodos de atividade incrementada durante o ciclo nictemeral, pode ser apreciada para as espécies diurnas e noturnas. Em relação às primeiras, tais aspectos geralmente ocorrem por ocasião do inicio da manhā e do fim da tarde. No caso das segundas, a mais das vezes, esses episódios são observados após o crepúsculo vespertino e antes do matutino, caracterizando ritmo de atividade ao qual se deu o nome de eo-crepuscular. A sua ocorrência, de forma abrupta, parece indicar subordinação predominantemente às condições microclimáticas (Haddow 11.13 1945, 1956). Estas dizem respeito, essencialmente, à temperatura e à umidade. Por sua vez, ao se considerar a limitada duração do intervalo crepuscular, a ocorrência de picos sugere a influência das condiçōes de luminosidade somadas às daqueles outros dois. Quanto às diferenças de intensidade entre as ondas vespertinas e as matutinas, estas geralmente menores do que aquelas, a temperatura parece ser o fator que as determina (Haddow 11.1. 19.45, 1964). Na região de Pariquera-Açú, e de maneira geral na do vale do rio Ribeira, a disponibilidade hidrica do solo mantém-se, durante todo o ano, em nivel excedente (Camargo ${ }^{3}, 1971$ ). Isso leva a admitir, sem apreciável risco de erro, que em ambos os intervalos crepusculares, a umidade nos níveis florestais baixos deva diferir de maneira pouco significante. Como - mesmo pode ser dito em relação às condições de luminosidade, é de se atribujr à temperatura as principais diferenças climáticas entre essas duas ocasiões, uma vez que o crepúsculo vespertino é relativamente mais quente do que o matutino, este podendo ser mesmo considerado como o períndo mais frio das 24 horas.

Posto isso, os dados conseguidos mediante observaçóes crepusculares e pericrepusculares permitem tecer algumas consideraçōes. Como se pode verificar pela análise dos gráficos constantes das Figuras 10 e 11 , exceção feita para o grupo de Phoniomyia sp. que se apresentou como estritamente diurno, para várias das espécies estudadas detectou-se incremento de atividade nos periodos crepusculares. Em observações focalizando o tempo póscrepuscular vespertino para mosquitos noturnos, levadas a efeito nos niveis situados acima da cobertura arbórea florestal, Haddow e col.1n (1968) associaram possivel ação desencadeante da atividade, ao momento em que se dá o máximo grau de alteração luminosa. No crepúsculo vespertino, isso corresponde a curto periodo relativo aos valores creps de 0,5 a 1,0 ou seja, à segunda metade do intervalo crepuscular e, conseqüentemente, de 1,0 a 0,5 , isto é, à primeira metade, no matutino. Nas presentes observações pôde-se distinguir, ao lado desse aspecto, outro que se traduz por estímulo momentâneo de atividade. Com efeito, nos resultados referentes às espécies noturnas, representados nos gráficos da Figura 11, revela-se o evidente caráter eo-crepuscular dos ciclos de $C q$. chrysonotum, $C q$. venezuelensis, $C x$. crybda e $C x$. vomerifer, e seu desencadeamento vespertino correspondente ao intervalo crep $0,5-1,0$. Por sua vez, a atividade diurna de $A e$. scapularis, Ae. serratus, Ps. albigenu e PS, ferox, constante dos gráficos da Figura 10 , mostra-se desencadeada no crepúsculo matutino no intervalo crep $1,0-0,5$. Por outro lado, em alguns deles tornou-se possivel observar a ocorrência de pico de curta duração nesses mesmos intervalos. Assim, verifica-se nitida onda vespertina (crep 0,5 1,0) nos diurnos Ae. scapularis e PS. albigenu, e matutina (crep $1,0-0,5$ ) nos noturnos $C x$. crybda e $C x$. vomerifer. É de se admitir pois, em tais oportunidades, a ação de fator estimulante que se sobrepõem à possivel tendência decrescente da atividade com à aproximação do crepúsculo vespertino, para os mosquitos predominantemente diurnos, e do matutino, para os noturnos. Tal particularidade não se observa em 
FORATTINI, O.P. et al. Observaçoes sobre atividade de mosquitos Culıcidae, em mata residual no Vale do Ribeira. S. Paulo, Brasil, Rer. Suíde púbt., S. Paulo, 15:557-86, 1981.

Ae. serratus e Ps. ferox, e nem em Cq. chrlsonotum e Cq. venezuelensis, respectivamente representantes daqueles dois tipos de hábito. Assim pois, apreciando-se os gráficos da Figura 8, e comparando-os com os acima referidos, pode-se concluir que, a semelhança que naqueles se observa entre os ciclos de Ae. scapularis e de Ae. serratus, desaparece por ocasiāo do crepúsculo vespertino, quando o primeiro passa a sobrepujar acentuadamente o segundo, no que concerne à atividade. O mesmo ocorre com Ps. albigenu e Ps. ferox, aquele comportando-se, nessa oportunidade, de maneira análoga a Ae. scapularis e este a Ae. serratus. $O$ mesmo se diga quanto às espécies noturnas em relação ao crepúsculo matutino, ocasiāo em que $C x$. crybda e $C x$. vomerifer incrementam momentâneamente sua atividade, o que não ocorre com $\mathrm{Cq}$. chrysonotum e $\mathrm{Cq}$. venezuelensis embora, como se pode ver na Figura 8, os quatro ciclos nictemerais sejam bastante comparáveis.

A explicação para esses vários aspectos das atividades crepusculares, obviamente não pode limitar-se à atuação de fatores de natureza endógena. É inegável a influência exógena $e$, dentre outros, as variações da intensidade luminosa constitui fator critico para o desencadeamento da atividade hematófaga (Haddow 1: 1964; Haddow e col.1: 1968). Além disso, a ele poderá tanbém ser atribuido papel no estimulo que resulta en acentuado e momentàneo incremento circunscrito ao intervalo crepuscular vespertino e matutino que se observa, respectivamente, em alguns mosquitos diurnos e noturnos. Tais ondas, para as quais pode-se adotar a denominação de picos endocrepusculares, revestem-se de particular significado pois representam retomada de atividade quando esta se encontra em aparente decréscimo. De qualquer maneira verifica-se que, ao lado de respostas a diferenças de temperatura que se registram quando da comparação dos dois crepúsculos, há que se admitir, para alguns mosquitos, a influência apreciável da oscilação luminosa que ocorre nessas oportunidades. Tal é o caso de Ae. scapularis, Ps. albigenu, $C x$. crybda e $C x$. vomerifer que encontram nesse fator estimulo para incremento de atividade, ao menos por parte de parcela de suas respectivas populações.

A ocorrência de pico endocrepuscular vespertino torna-se particularmente significativa ao se considerar a possibilidade de transmissão de infecções por parte desses culicídeos. Com efeito, levando-se em conta que várias atividades humanas são realizadas nesse periodo, claro está que os mosquitos que apresentem esse tipo de comportamento teriam maiores oportunidades de contatos com o homem. Nesse particular, destaca-se, nos presentes estudos, o Ae. scapularis. Sendo esse mosquito de hábitos predominantemente diurnos, nem por isso deixa de mostrar apreciável atividade noturna. A esse quadro geral soma-se significante incremento vespertino. Diante desses aspectos, forçoso torna-se considerar essa população culicidea como altamente importante, sob o ponto de vista epidemiológico.

No que concerne à dominância, entendida como presença nas coletas, a análise dos dados obtidos teriam de se concentrar em relaçāo às duas citadas espécies de Aedes. Eis que, mais do que os demais, esses mosquitos mostraram considerável constância de comparecimento nas capturas, e em niveis significantes. Nesse particular pois, a distribuiçâo horária dos dados obtidos nos três tipos de coleta, revelaram predominância de Ae. serratus sobre Ae. scapularis no meio florestal, e deste sobre aquele no ambiente aberto, fora da mata residual. A observação dos gráficos representados na Figura 12 mostra que, além daquele predomínio nāo ser relevante, o Ae. scapularis manteve estabilidade de comparecimento em todos os tipos de coleta e, consequientemente, nos dois mencionados ambientes. Isso permite ponderar a ubiqüidade desse culicideo, naior do que a de Ae. serratus, o qual parece ter pouca tendência a exercer sua atividade fora do ambiente florestal residual. Por sua vez, a distribuição mensal dos dados conseguidos no interior da mata, se revelam a já 
FORATTINI, O.P. et al. Observaçoes sobre atividade de mosquitos Culicidae, em mata residual no Vale do Ribeira, S. Paulo, Brasil, Rev. Saüde públ., S. Paulo, 1z:557-86, 1981.

mencionada predominânciá geral de Ae. serratus, mostra flagrante exceção no mês de junho. Os gráficos da Figura 13 mostram, de maneira nítida, o predomínio de Ae. scapularis nessa oportunidade, tanto nas coletas com isca humana como com armadilha tipo Shannon, nesse meio. E esse aspecto também se evidencia marcadamente nos resultados obtidos com a utilização do mesmo tipo de armadilha, mas operada no meio aberto. Aqui, se bem que o predomínio geral seja desse mosquito, em relação ao outro acentua-se marcadamente no mês de junho. A explicação para esse fenômeno requer ulteriores pesquisas. Ao que parece, a menor pluviosidade e os menores niveis de temperatura que se registram nessa época, podem ter algo a ver com esse quadro. E isso embora, algumas observaçōes, levadas a efeito em outras regiões tenham assinalado a concordância entre a densidade desse mosquito e as precipitaçōes atmosféricas (Kruijf 19 1972; Neves e Silva 23 1973). Eis que Ae. scapularis, nesse particular, comportou-se de maneira diferente das demais espécies, como se pode verificar pela distribuição mensal das médias, representada nos gráficos da Figura 14. Assim sendo, além da constância de seu comparecimento nas diversas horas do ciclo nictemeral, acrescenta-se feição análoga quanto aos dois ambientes, intra e extraflorestal, e aos vários meses do ano. Neste último caso, com nítido pico junino, correspondendo ao periodo hibernal. Tal comportamento apresenta aspectos que reforçam a hipótese que atribui a esse culicídeo elevada possibilidade de contato com a população humana e, assim, de revestir-se de considerável importância epidemiológica.

Diante dessas considerações, torna-se evidente que os resultados obtidos nas presentes pesquisas vão ao encontro das conclusões decorrentes das anteriormente realizadas na mesma região (Forattini e col.i.8 1978). Parece evidente que, pelo menos no ambiente extradomiciliar de áreas que sāo sede de intensa atividade agropecuária dessa região do Vale do Ribeira, o
Aedes scapularis e o Ae. serratus apresentam grandes possibilidades de contato com a população humana local. Desta forma, no caso em foco, de transmitirem agentes infecciosos. Em especial modo, a primeira dessas espécies mostra apreciável valência ecológica, revelada pela presença constante, tanto temporal como espacial, de sua atividade hematófaga. Claro está que não se exclui a possível participação de outros mosquitos na veiculação, no caso em foco, de arboviroses e, de maneira particular, de encefalites. No entanto, o potencial representado por aqueles culicídeos é considerável, levando à inevitável hipótese de sua responsabilidade vetora em relação ao homem.

\section{CONCLUSÕES}

1. Em mata residual do Vale do Ribeira localizada em área de ambiente alterado, sede de atividades agropecuárias, os culicídeos Aedes scapularis e Ae. serratus mostraram freqüência continua para a isca humana, no período das 24 horas.

2. Embora ambos esses mosquitos aumentem sua atividade nos periodos pericrepusculares, o Ae. scapularis apresenta nítido pico endocrepuscular vespertino, que não se observa em Ae. serratus.

3. Pico análogo verifica-se na atividade de Psorophora albigenu, além de, no crepúsculo matutino, na de Culex crybda e $C x$. vomerifer.

4. É nítida a influência crepuscular como desencandeante da atividade culicidea. Para os mosquitos diurnos esse papel ocorre no crepúsculo matutino, e no vespertino para os noturnos. Estes, representados por Coquillettidia chrysonotum, Cq. venezuelensis, Culex crybda e $C x$. vomerifer mostram nitido ritmo eo-crepuscular.

5. A atividade de Ae. scapularis nāo sofre sensivel alteração, quanto aos ambientes intra e extraflorestal, enquanto a do Ae. serratus parece limitar-se àqueles. 
FCRATTINI, O.P. et al. Observações sobre atividade de mosquitos Culicidae, em mata residlaal no Vale do Ribeira, S. Paulo, Brasil, Rev. Saúde públ., S. Paulo, 15:557-86, 1981.

6. Tanto Ae. scapularis como Ae. serratus ocorrerem durante todos os meses do ano, com máior intensidade para o primeiro no periodo hibernal, em particular, no mês de junho. Tal feição necessita de ulteriores estudos para sua explicação.
7. As caracteristicas de comportamento de Ae. scapularis são de molde a permitir associar esta espécie com a provável transmissão local de arboviroses, em especial modo encefalites, à população humana.

FORATtiNi, $O$. P. et al. [Observations on mosquito activity in residual forest in the Ribeira Valley, S. Paulo, Brazil]. Rev. Saúde públ., S. Paulo, 15:557-86, 1981.

ABSTRACT: The results of fortnightly 25-hour catches of Culicidae mosquitoes carried out at ground level with human bait in a residual forest area of the Ribeira Valley, S. Paulo, Brazil, are presented and discussed. Besides this, regular simultaneous catches with Shannon traps were made within and outside the forest environment. Daily biting cycles showed diurnal and nocturnal behaviour patterns which distinguished the nine most frequent species. Even through Ae. scapularis and Ae. serratus show a clear diurnal pattern they sustain moderate activity at night. Ae. scapularis also presents a clear peak of biting activity during the sunset-crepuscular period (corresponding to crep. $0.5-1.0$ ) and sustain their activity outside the forest at an equivalent density to that inside it. The monthly pattern throughout the year showed the constant presence of both mosquitoes, with a June predominance of Ae. scapularis. These data enable one to admit that this mosquito has greater opportunities of contact with the human population and thus relatively greater probability of transmitting arboviruses such as those of encephalitis.

UNITERMS: Culicidae, ecology. Aedes scapularis. Aedes serratus. Arbovirusis. Ribeira Valley, SP, Brazil.

\section{REFERENCIAS BIBLIOGRĀFICAS}

1. AITKEN, T.H.G. et al. Arborirus studies in Bush Bush forest, Trinidad, W.I., September 1959 - December 1964. II Field program and techniques. Amer, $J$. trop. Med. Hyg., 17:237-52. 1968.

2. AITKEN, T.H.G. et al. Arbovirus studies in Bush Bush forest, Trinidad, W.I., September 1959 - December 1964. III Entomological studies. Amer. $J$. trop. Med. Hyg., $17: 253-68,1968$.

3. CAMARGo, A.P. de Balango hidrico no Estado de São Paulo. São Paulo, Instituto Agronômico, 1971. (Boletim, 116).

4. CLEMENTS, A.N. The physiology of mosquitoes. Oxford. Pergamon Press, 1968.
5. COLLESS, D.H. Components of the catch curve of Culex annulus in singapore. Nature, $180: 1496-7.1957$.

6. DEGALLIER, N. et al. Rythmes dactivité des Culicidés de la Guyane française (Diptera, Culicidae). Cah. O.R.S.T.O.M. Ent. méd. parasit., 16:73-84,1978.

7. FORATtiNI, O.P. et al. Estudos ecológicos sobre mosquitos Culicidae no sistema da Serra do Mar, Brasil. 1 - Observações no ambiente extradomiciliar. Rev. Saude públ., S. Paulo, 12:297-325, 1978.

8. FORATtini, O.P. et al. Estudos ecológicos sobre mosquitos Culicidae no sistema da Serra do Mar, Brasil. 2 - Observações no ambiente domiciliar. Rev. Saúde públ., S. Paulo, $12: 476-96,1978$. 
FORATTINI, O.P. et al. Observaçōes sobre atividade de mosquitos Culicidae, em mata residral no Vale do Ribeira, S. Paulo, Brasil, Rev. Saúde públ., S. Paulo, 15:557-86, 1981.

9. GALINDO, P. et al. An ecological survey for arboriruses in Almirante, Panama, 1959-1962. Amer. J. trop. Med. Hyg, $15: 385-400,1966$.

10. GERMAIN, M. et al. Observations sur l'écologie et le comportement particuliers d'Aedes africanus (Theobald) dans le nord du Cameroun occidental. Cah. O.R.S.T.O.M. Ent. med. Partsit., 10:119-26. 1972

11. HADDOW, A.J. The mosquitoes of Bwamba County, Uganda. II - Biting activity with special reference to the influence of microclimate. Bull, ent. Res., 36:33-73, 1945 .

12. HADDOW, A.J. Observations on the biting habits of mosquitoes in the forest canopy at Zika, Uganda, with special reference to the crepuscular periods. Bull. ent. Res., 55:395-608, 1964.

13. HADDOW, A.J. Rhythmic biting activity of certain east african mosquitoes. $\mathrm{Na}$ ture, 177:531-2, 1956.

14. HADDOW, A.J. Studies on the biting-habits of african mosquitoes: an appraisal of methods employed. with special reference to the twenty-four-hour catch. Bull. ent. Res., t5:199-242, 1954.

15. HADDOW, A.J. Studies on the biting habits and medical importance of east African mosquitoes in the genus Aedes. I - Subgenera Aedimorphus, Banksinella and Dunnius. Bull. ent. Res. 50: $759-79,1960$.

16. HADDOW, A.J. et al. Entomological studies from a high steeltower in Zika forest, Uganda. Part II - The biting activity of mosquitoes above the forest canopy in the hour after sunset. Trans. roy. ent. Soc. Lond., 120:219-36. 1968.

17. KNIGHT, K.L. Supplement to a Catalog of the mosquitoes of the world (Diptera: Cl:licidae). College Park, Md., Entomological Society of America, 1978.

18. KNIGHT, K.L. \& STONE, A. A catalog of the mosquitoes of the world (Diptera: Culicidae). College Park, Md., Entomological Society of America, 1977.

19. KRUIJF, A.M. de Aspects of the ecology of mosquitoes in Surinam. Studies on the Fauna of Suriname and other Guyanas, 13(51):1-56. 1972 .

20. LOPES, $O$ de $S$, et al. Emergence of a new arbovirus disease in Brazil. III Isolation of Rocio virus from Psorophora ferox (Humboldt, 1819), Amer. $T$. Epidem., 113:122-5, 1981.

21. LUMSDEM, W.H.R. The crepuscular biting activity of insects in the forest canopy in Bwamba, Uganda. A study in relation to the sylvan epidemiology of yellow fever. Bull. ent. Res., 42:721-60, 1952.

22. MeCRAE, A.W.R. et al. The behavioural ecology of host selection in Anopheles implexus (Theobald) (Diptera, Culicidae). Bull. ent. Res., 66:587-631, 1976.

23. NEVES, D.P. \& SILVA, J.E. da Aspectos da biologia dos culicinae do Parque das Mangabeiras, Belo Horizonte. I - Es. pécies locais e variação estacional. Arq. Esc. Vet., Belo Horizonte, 25:287-98, 1973.

24. NIELSEN, E.T. Illumination at twilight. Oikos, 14:9-21, 1963.

25. NIELSEN, E.T. Twilight and the "crep" unit. Nature, 190:878-9, 1961.

26. REINERT, J.F. Mosquito generic and subgeneric abbreviations (Diptera: Culicidae). Mosq. System., 7:105-10, 1975.

27. SAUNDERS, D.S. Insect clocks. Oxford, Pergamon Press, 1976.

28. SAUNDERS, D.S. Insect photoperiodism: the clock and the counter: a review. Physiol. Ent., 6:99-116, 1981.

29. SIRIVANAKARN, S. \& BELIIN, J. The identity of Culex (Melanoconion) taeniopus Dyar and Knab and related species with notes on the synonymy and description of a new species (Diptera, Culicidae). Mosq. System., 12:7-20, 1980.

30. SOUTHWOOD, T.R.E. Ecological methods. 2nd ed. London. Chapman and Hall, 1978.

Recebido para publicaşão em 24/09/1981

Aprovado para publicasão em 17/11/1981 